\title{
Selective enzymatic release and gel formation by crosslinking of feruloylated glucurono-arabinoxylan from corn bran
}

Munk, Line; Muschiol, Jan; Li, Kai; Liu, Ming; Perzon, Alixander; Meier, Sebastian; Ulvskov, Peter; Meyer, Anne S.

\section{Published in:}

ACS Sustainable Chemistry \& Engineering

Link to article, DOI:

10.1021/acssuschemeng.0c00663

Publication date:

2020

Document Version

Peer reviewed version

Link back to DTU Orbit

Citation (APA):

Munk, L., Muschiol, J., Li, K., Liu, M., Perzon, A., Meier, S., Ulvskov, P., \& Meyer, A. S. (2020). Selective enzymatic release and gel formation by crosslinking of feruloylated glucurono-arabinoxylan from corn bran. ACS Sustainable Chemistry \& Engineering, 22(8), 8164-8174. https://doi.org/10.1021/acssuschemeng.0c00663

\section{General rights}

Copyright and moral rights for the publications made accessible in the public portal are retained by the authors and/or other copyright owners and it is a condition of accessing publications that users recognise and abide by the legal requirements associated with these rights.

- Users may download and print one copy of any publication from the public portal for the purpose of private study or research.

- You may not further distribute the material or use it for any profit-making activity or commercial gain

- You may freely distribute the URL identifying the publication in the public portal 


\title{
Selective enzymatic release and gel formation by cross- linking of feruloylated glucurono-arabinoxylan from corn bran
}

\author{
Line Munk, Jan Muschiol, Kai Li, Ming Liu, Alixander \\ Perzon, Sebastian Meier, Peter Ulvskov, and Anne S Meyer \\ ACS Sustainable Chem. Eng., Just Accepted Manuscript • DOI: 10.1021/ \\ acssuschemeng.0c00663 Publication Date (Web): 11 May 2020
}

Downloaded from pubs.acs.org on May 18, 2020

\section{Just Accepted}

"Just Accepted" manuscripts have been peer-reviewed and accepted for publication. They are posted online prior to technical editing, formatting for publication and author proofing. The American Chemical Society provides "Just Accepted" as a service to the research community to expedite the dissemination of scientific material as soon as possible after acceptance. "Just Accepted" manuscripts appear in full in PDF format accompanied by an HTML abstract. "Just Accepted" manuscripts have been fully peer reviewed, but should not be considered the official version of record. They are citable by the Digital Object Identifier (DOI®). "Just Accepted" is an optional service offered to authors. Therefore, the "Just Accepted" Web site may not include all articles that will be published in the journal. After a manuscript is technically edited and formatted, it will be removed from the "Just Accepted" Web site and published as an ASAP article. Note that technical editing may introduce minor changes to the manuscript text and/or graphics which could affect content, and all legal disclaimers and ethical guidelines that apply to the journal pertain. ACS cannot be held responsible for errors or consequences arising from the use of information contained in these "Just Accepted" manuscripts. 


\section{Selective enzymatic release and gel formation by cross-linking of feruloylated 2 glucurono-arabinoxylan from corn bran}

3 Line Munk ${ }^{1, \sharp}$, Jan Muschiol ${ }^{1, \$}$, Kai Li ${ }^{1}$, Ming Liu ${ }^{1}$, Alixander Perzon², Sebastian Meier ${ }^{3}$, Peter

$4 \quad$ Ulvskov $^{2}$, Anne S. Meyer ${ }^{1, *}$

$5 \quad{ }^{1}$ Protein Chemistry and Enzyme Technology, DTU Bioengineering, Department of

6 Biotechnology and Biomedicine, Technical University of Denmark, Søltofts Plads 221, DK-2800

7 Kgs. Lyngby, Denmark.

$8 \quad{ }^{2}$ Department of Plant and Environmental Sciences, University of Copenhagen, Thorvaldsensvej

9 40, DK-1871 Frederiksberg C, Denmark.

$10{ }^{3}$ Department of Chemistry (DTU Chemistry), Technical University of Denmark, Kemitorvet 207,

11 DK-2800 Kgs. Lyngby, Denmark.

12

$13 *$ *Corresponding author: e-mail asme@dtu.dk (Anne S. Meyer), postal address as above.

14 \$These authors contributed equally. 


\section{ABSTRACT}

16 Corn bran is a major agro-industrial byproduct from corn starch processing. The bran is

17 particularly rich in highly substituted feruloylated glucuronoarabinoxylan (FGAX). Yet, due to

18 its recalcitrance to biocatalytic degradation, corn bran FGAX is currently not utilized in

19 biorefinery processes. Here, we report selective enzymatic extraction of both single, and double-

20 stranded high-molecular-weight FGAX molecules from corn bran using a bacterial, glucuronoyl-

21 specific glycoside hydrolase family 30 endo-1,4- $\beta$-xylanase (EC 3.2.1.8) from Dickeya

22 chrysanthemi (DcXyn30). The enzymatic extraction using DcXyn30 was optimized with respect

23 to temperature, $\mathrm{pH}$, and time to maximize yields of high-molecular-weight polysaccharides.

24 Examination of the enzymatically extracted FGAX using SEC, HPAEC, LC-MS, and NMR

25 analysis (after acid or alkaline hydrolysis) revealed that both single-stranded and double-stranded

26 FGAX were extracted, since diferulate-linkages were present in the extracted FGAX.

27 Furthermore, the NMR-analysis indicated presence of 1,5-linked arabinan dimers suggesting that

28 some of the xylopyranosyl residues in the extracted FGAX contained arabinofuranosyl-

29 arabinofuranosyl substitutions in addition to a significant amount of classical doubly-arabinose

30 substitutions. Laccase treatment of the extracted FGAX produced strong hydrogels via oxidative,

31 covalent feruloyl-cross-linking. At pH 6.5 the Myceliophthora thermophila derived laccase

32 produced significantly faster cross-linking kinetics than the laccase from Pleurotus ostreatus as

33 measured rheologically. The data reveal novel insight into corn bran FGAX chemistry and

34 provide a new direction for enzyme-assisted upgrading of corn bran for valuable functional

35 hydrogel applications.

37 KEYWORDS: glycoside hydrolase family 30 xylanase; dehydrodiferulates; laccase; hydrogel 


\section{Introduction}

39 Corn bran is an agro-industrial residue stream resulting from corn starch processing. The corn 40 bran consists of the hulls of the maize kernels (pericarp and seed coat), and make up approx. 5\%

41 of the total kernel weight. ${ }^{1}$ Based on recent data on global corn production (1101.2 million

42 metric tons in $2018 / 2019)^{2}$ the annual co-processing production of corn bran amounts to approx.

4355 million metric tons per year. The bran is mainly used as an animal feed supplement due to its

44 high insoluble fiber content (up to $86 \%$ (w/w)), which mainly consists of complex hemicellulose 45 polysaccharides, notably highly substituted xylan. ${ }^{3}$ Detailed analyses of corn bran xylan have

46 revealed that the xylan backbone is heavily substituted with arabinosyl residues, and both mono-

47 and di-substituted xylosyl residues with substitutions at positions $\mathrm{O} 2$ and/or $\mathrm{O} 3$ are present. ${ }^{4} \mathrm{In}$

48 addition, presence of 4-O-methyl-glucuronoyl, L- galactosyl and oligomeric arabinosyl

49 substitutions, ${ }^{5-8}$ as well as and acetylation of the xylan backbone at $\mathrm{O} 2$ and $\mathrm{O} 3$ of the xylosyl

50 moieties, and esterification of the arabinosyl residues with ferulic acid at $\mathrm{O} 5$ have been described

51 in the literature. ${ }^{9-11}$ Hence, corn bran xylan is referred to as feruloylated glucuronoarabinoxylan

52 (FGAX). The reported ferulic acid content of corn bran is $33 \mathrm{mg} / \mathrm{g}$ insoluble fibre, which is

53 almost five times higher than that of other cereal brans (for wheat and barley typical levels are

$54 \sim 7 \mathrm{mg} / \mathrm{g}$ insoluble fibre). ${ }^{12}$ The feruloyl substitutions make corn bran FGAX attractive as a

55 source of potential antioxidant and prebiotic oligomers that may be applied in foods. ${ }^{13-15}$

56 Alternatively, the FGAX can be used in functional or structural material applications since the

57 feruloylated chains can be covalently cross-linked to diferulates (dehydrodiferulates, DiFAs) via

58 oxidative enzymatic catalysis using either laccase or peroxidase to form strong hydrocolloid

59 gels. ${ }^{16,17}$ Classical chemical extraction methods of xylan from corn bran usually involve use of

60 high concentrations of $\mathrm{HCl}$ or $\mathrm{NaOH}$ and high temperatures (up to $100^{\circ} \mathrm{C}$ ) - methods that are 
61 now considered inexpedient and which furthermore may lead to saponification of the ester

62 modifications of the xylan. ${ }^{4}$ Rapid, microwave-assisted hydrothermal extraction methods lead to

63 the formation of unwanted byproducts such as furfural..$^{18}$ More recently, the extraction of

64 hemicellulose from wheat bran by subcritical water (pressurized hot water up to $160^{\circ} \mathrm{C}$ ) was

65 shown to result in high yields and to preserve the valuable feruloylations in extracted FGAX, but

66 the methodology also led to significant co-extraction of $\beta$-glucans and starch. ${ }^{19,20}$ Therefore, it

67 would be highly desirable to establish mild selective enzymatic extraction methods for FGAX

68 from corn bran at low temperatures and moderate $\mathrm{pH}$ values, i.e. methods not requiring use of

69 hazardous chemicals and not producing undesirable byproducts.

70 The less substituted xylans from other cereal sources are easily degraded by microbial endo-

71 xylanases categorized in glycoside hydrolase (GH) families 10 and 11, and many such endo-

72 xylanases, including inhibitor-resistant versions, have been commercially available for a decade

73 and are of significance in baking and biofuel processes. ${ }^{21,22}$ In contrast, the recalcitrance of raw

74 corn bran towards enzymatic hydrolysis has hampered industrial biorefining of corn bran

75 glucuronoarabinoxylans for creation of products for higher value applications. ${ }^{23}$ Hence, in the

76 native, highly substituted corn bran arabinoxylan there are essentially no regions of unsubstituted

77 xylosyl residues available for recognition and cleavage by the GH10 and GH11 xylanases.

78 However, endo-xylanases belonging to subfamily 8 of GH family 30 (GH30_8) have a

79 glucuronosyl (GlcA) or 4-O-methyl-GlcA residue as recognition site, ${ }^{24}$ and have been described

80 to be active on corn xylan. ${ }^{25}$ The hitherto described GH30_8 xylanases will thus catalyze

81 hydrolytic cleavage of the xylan backbone at the second glycosidic linkage next to the GlcA

82 branching (counted from the reducing end). ${ }^{26,27}$ Based on this rare recognition site of GH30_8

83 xylanases, we hypothesized that high-molecular weight FGAX could be selectively extracted

84 from corn bran via GH30_8 xylanase catalysis, and in turn, that such extracted FGAX could be 
85 cross-linked via oxidative enzyme catalyzed formation of DiFAs to form hydrogels for novel

86 food or material science applications. A number of GH30 xylanases originating from bacteria

87 and fungi have been described, several of them recently, e,g. from Bacillus sp. BP-7, ${ }^{28}$ B.

88 substilis, ${ }^{29}$ B. licheniformis, ${ }^{30}$ Clostridium acetobutylicum, ${ }^{31}$ C. papyrosolvens, ${ }^{32}$ Streptomyces

89 turgidiscabies, ${ }^{33}$ Talaromyces cellulolyticus, ${ }^{34}$ Thermothelomyces thermophila ${ }^{35}$ (synonym

90 Myceliophthora thermophila), and Trichoderma reesei ${ }^{36}$. However, in particular the endo-

91 xylanase, DcXyn30, from Dickeya chrysanthemi (previously known as Erwinia chrysanthemi pv.

92 zeae or Dickeya zeae $)^{26,27,37-40}$ caught our attention, because D. chrysanthemi is a maize

93 pathogen. ${ }^{40-43}$ Although this pathogenicity has been known for almost 60 years, ${ }^{44}$ the reactivity

94 of DcXyn30 towards corn bran FGAX has to our knowledge not been reported. Here, we show

95 the usefulness of DcXyn30 for controlled enzymatic extraction of soluble and high-molecular

96 weight FGAX polysaccharides from corn bran and demonstrate the applicability of the extracted

97 FGAX molecules to form hydrogels via laccase-catalyzed cross-linking of the feruloyl residues.

98

\section{$99 \quad$ Materials and Methods}

100 Materials. The raw corn bran was supplied by Archer Daniel Midlands Co. (Decatur, IL, USA) 101 and destarched as previously described. ${ }^{45}$ Subsequently, the material was ball milled (MM-200, 102 Retsch GmbH, Haan, Germany) with a frequency of $30 \mathrm{~s}^{-1}$ for $3 \mathrm{~min}$. The composition of the raw 103 material was determined according to the laboratory analytical procedure from the US National 104 Renewable Energy Laboratory. ${ }^{46}$ All other chemicals were at least of analytical grade and were 105 used without further treatment or purification, unless stated otherwise.

106 Cloning, expression and purification of the DcXyn30 enzyme. The protein sequence of 107 DcXyn30 was retrieved from the GenBank database (accession no. ACZ76867.1). The signal 
108 peptide was detected using the SignalP server $4.1^{47}$ and the amino acid sequence without signal

109 peptide was submitted to GenScript (Piscataway, NJ) for synthesis of a codon-optimized gene for

110 expression in Escherichia coli. Subcloning into pPAL7 (Bio-Rad Laboratories Inc., Hercules,

111 CA, USA) using the HindIII and XhoI restriction sites was carried out by GenScript. The

112 resulting plasmid, pPAL7_DcXyn30, was transformed into E. coli DH5 $\alpha$ for maintenance and

113 into E. coli BL21 (DE3) for expression using Mix\&Go competent cells (Zymo Research, Irvine,

114 CA, USA). The gene encoding the enzyme was expressed in a simplified auto-induction medium

$115\left(6 \mathrm{~g} / \mathrm{L} \mathrm{Na}_{2} \mathrm{HPO}_{4}, 3 \mathrm{~g} / \mathrm{L} \mathrm{KH}_{2} \mathrm{PO}_{4}, 20 \mathrm{~g} / \mathrm{L}\right.$ tryptone, $5 \mathrm{~g} / \mathrm{L}$ yeast extract, $5 \mathrm{~g} / \mathrm{L} \mathrm{NaCl}, 0.6 \%(\mathrm{v} / \mathrm{v})$

116 glycerol, $0.05 \%(\mathrm{w} / \mathrm{v})$ glucose, $0.2 \%(\mathrm{w} / \mathrm{v})$ lactose) containing $50 \mu \mathrm{g} / \mathrm{ml}$ ampicillin as selection

117 marker. To this end, $5 \mathrm{ml}$ of a pre-culture were inoculated into $400 \mathrm{~mL}$ of medium in a $2 \mathrm{~L}$ -

118 Erlenmeyer flask with baffles and incubated for $2 \mathrm{~h}$ at $37^{\circ} \mathrm{C}$ and $160 \mathrm{rpm}$. Afterwards, the

119 temperature was adjusted to $20^{\circ} \mathrm{C}$ and the cultivation was continued overnight. The cells were

120 harvested by centrifugation ( $4500 \mathrm{~g}, 10 \mathrm{~min})$ and either lysed by ultrasound ( 0.6 cycle, $100 \%$

121 amplitude on a UP400S, Hielscher Ultrasonics GmbH, Teltow, Germany) or by a bench-top

122 high-pressure homogenizer using one passage at $40 \mathrm{mbar}$, followed by a passage at $1 \mathrm{bar}$

123 ('Pressure Cell' Homogenizer, Stansted Fluid Power Ltd, Essex, UK). The cell debris was

124 removed by centrifugation at $20,000 \mathrm{~g}$ for $20 \mathrm{~min}$ at $4^{\circ} \mathrm{C}$. The enzyme was purified using the

125 Profinity eXact ${ }^{\mathrm{TM}}$ Fusion-Tag System (Bio-Rad Laboratories Inc.) following the manufacturer's

126 instructions for FPLC system assisted purification (ÄKTA purifier, GE Healthcare, Uppsala,

127 Sweden). Re-loading of the flow-through up to five times increased the yield of enzyme.

128 Afterwards the enzyme containing fractions were either collected and concentrated to $2.5 \mathrm{~mL}$

129 followed by desalting using the gravity protocol on PD-10 columns as indicated in the manual

130 (GE Healthcare) or desalted directly without a prior concentration step using five HiTrap

131 Desalting columns (each $5 \mathrm{ml}$ ) that were connected in series to the ÄKTA purifier following the 
132 manufacturer's manual (GE Healthcare). Purity was checked by SDS-PAGE (Mini-PROTEAN ${ }^{\circledR}$

133 TGX ${ }^{\mathrm{TM}}$ Precast Gels, Bio-Rad) and the protein concentration was determined using a

134 commercial Bradford assay kit (Roti ${ }^{\circledR}$-Nanoquant, Carl Roth GmbH + Co. KG, Karlsruhe,

135 Germany) with bovine serum albumin as calibration standard.

136 Optimization of the FGAX extraction process. A 3-level full factorial design was carried out to 137 establish optimal conditions in terms of $\mathrm{pH}$ and temperature for the activity of DcXyn30 on the 138 destarched corn bran at 10\% dry matter (DM) concentration. Based on preliminary experiments 139 the enzyme dose was set to $0.010 \mathrm{mg} / \mathrm{ml}$. Each variable ( $\mathrm{pH}$ and temperature) was considered at 140 three levels including a center point (in triplicates), which represented the midpoint of each

141 factor range. Based on preliminary experiments, the levels were set to $\mathrm{pH} 4-7$ and $25-65^{\circ} \mathrm{C}$

$142\left(\mathrm{pH} 5.5,45^{\circ} \mathrm{C}\right.$ as center point) giving a total of 12 experiments. The release of FGAX was

143 observed over 60 min by measuring reducing ends in the supernatant with xylose as standard.

144 Samples taken after 60 min were also analyzed by size exclusion chromatography (SEC). The

145 response values for the factorial design were given as the maximal release after $60 \mathrm{~min}$ in terms

146 of reducing ends and area of the elution peak from $5 \mathrm{kDa}-110 \mathrm{kDa}$ according to pullulan

147 standards. The statistical design program JMP 14 (SAS Institute Inc., Cary, NC, USA) was used

148 as an aid to statistically design the factorial experiments and to fit and analyze the data by

149 multiple linear regression. Significance of the results was established at $p<0.05$.

150 Extraction of soluble, high-molecular weight FGAX. FGAX polysaccharides were extracted

151 from $10 \%$ DM destarched corn bran at $\mathrm{pH} 5.5$ at $45^{\circ} \mathrm{C}$ for $2 \mathrm{~h}$ with DeXyn30 at $0.010 \mathrm{mg} / \mathrm{ml}$

152 under gentle shaking. The $\mathrm{pH}$ in the slurry was adjusted with $0.1 \mathrm{M} \mathrm{HCl}$. The supernatant was

153 collected after $20 \mathrm{~min}$ of centrifugation at $4400 \mathrm{rpm}$. The pellet was washed in Milli-Q water and

154 the supernatants were pooled after centrifugation. The resulting extract was left overnight to 
155 precipitate in $90 \%$ ethanol. The precipitate was collected after centrifugation for $20 \mathrm{~min}$ at 4400

$156 \mathrm{rpm}$ and dried overnight at $40{ }^{\circ} \mathrm{C}$.

157 Characterization of the extracted FGAX. All characterizations of the enzymatically extracted

158 FGAX were carried out using a solution of $2 \%(\mathrm{w} / \mathrm{v})$, which was prepared by dissolving the 159 precipitated dried extract in $\mathrm{pH}$-adjusted water $(\mathrm{pH}$ 5.5) followed by centrifugation for $5 \mathrm{~min}$ at $16014,000 \mathrm{~g}$ to remove insoluble material. For determination of the molecular weight distribution of 161 the FGAX extract before and after precipitation SEC was performed using an Ultimate iso-3100 162 SD pump with a WPS-3000 sampler (Dionex, ThermoFisher Scientific, Waltham, MA, USA) 163 connected to an RI-101 refractive index detector (Showa Denko K.K., Tokyo, Japan). $100 \mu \mathrm{L}$ of 164 the sample was loaded on a Shodex SB-806 HQ GPC column (300 x $8 \mathrm{~mm})$ equipped with a 165 Shodex SB-G guard column (50 mm x $6 \mathrm{~mm}$ ) (Showa Denko K.K.). Elution was performed with $166100 \mathrm{mM}$ sodium acetate at a flow rate of $0.5 \mathrm{~mL} / \mathrm{min}$ at $40^{\circ} \mathrm{C}$. Pullulan standards were used as 167 reference molecular weight standards.

168 Monosaccharide composition was determined as previously described using $4 \% \mathrm{H}_{2} \mathrm{SO}_{4}$ 169 hydrolysis for 1 hour and analysis by high-performance anion exchange chromatography 170 (HPAEC) with pulsed amperometric detection. ${ }^{45}$ Ferulic acid (FA) and diferulic acids (diFAs)

171 were identified and quantified by LC-MS on a Dionex UltiMate 3000 UHPLC system (Thermo

172 Fischer Scientific, Sunnyvale CA, USA) connected to an ESI-iontrap (model AmaZon SL, 173 Bruker Daltonics, Bremen, Germany). For FA and DiFA determination, the samples were 174 saponified with $1 \mathrm{M} \mathrm{NaOH}$ overnight at $25^{\circ} \mathrm{C}$ in absence of $\mathrm{O}_{2}$. Then, $\mathrm{pH}$ was lowered to $\mathrm{pH}<2$ 175 and $25 \%$ (v/v) acetonitrile was added to the samples prior to LC-MS analysis. $5 \mu \mathrm{L}$ sample were 176 injected onto a Hypersil Gold Phenyl column $(150 \mathrm{~mm} \times 2.1 \mathrm{~mm}, 3 \mu \mathrm{m}$; Thermo Fisher 177 Scientific). The chromatography on the Dionex UltiMate 3000 UPLC was operated at 0.4 $178 \mathrm{~mL} / \mathrm{min}$ at $40^{\circ} \mathrm{C}$ with a three-eluent system with elution using A: $0.1 \%$ formic acid in water; 
179 eluent B: acetonitrile; eluent C: water as follows: 0 min, 10\% A/0\% B/90\% C; $0-15$ min, linear 180 gradient to $10 \% \mathrm{~A} / 50 \% \mathrm{~B} / 40 \% \mathrm{C} ; 15-20$ min, isocratic $10 \% \mathrm{~A} / 50 \% \mathrm{~B} / 40 \% \mathrm{C} ; 20-25$ min, 181 isocratic $10 \% \mathrm{~A} / 0 \% \mathrm{~B} / 90 \% \mathrm{C}$. The electrospray was operated in negative scan mode using a 182 target mass of $400 \mathrm{~m} / \mathrm{z}$ with a scan range from 100 to $2000 \mathrm{~m} / \mathrm{z}$ with parameter settings as 183 follows: capillary voltage $4.5 \mathrm{kV}$, end plate offset $0.5 \mathrm{kV}$, nebulizer pressure 3.0 bar, dry gas 184 flow $12.0 \mathrm{~L} / \mathrm{min}$, dry gas temperature $280^{\circ} \mathrm{C}$. FA was quantified by ferulic acid standard curves 185 at $280 \mathrm{~nm}$. DiFAs were identified by a combination of MS and UV spectra. ${ }^{48,49}$ Response factors 186 from Waldron et al. ${ }^{48}$ were used to quantify the DiFAs..$^{50}$

187 Acetate content was determined using the Acetic Acid Assay Kit (Acetate Kinase Analyser 188 Format) from Megazyme (Bray, Ireland) according to the manufacturer's manual.

189 NMR spectra were recorded on lyophilized, enzymatically extracted FGAX after precipitation 190 after re-dissolution in $0.6 \mathrm{ml} \mathrm{D} 2 \mathrm{O}$. All spectra were acquired at $50^{\circ} \mathrm{C}$ using a Bruker Avance III $191800 \mathrm{MHz}$ spectrometer (Bruker, Fällanden, Switzerland) equipped with a TCI cryoprobe. The 192 acquired spectra included a 1D proton spectra sampling 16384 complex data point during an 193 acquisition time of 1.3 seconds. Homo- and heteronuclear 2D NMR spectra were additionally 194 acquired. The 2D NMR spectra included TOCSY with a $10 \mathrm{kHz}$ spin lock field that was applied 195 for $60 \mathrm{~ms}(1024 \times 256$ complex data points with $213 \mathrm{~ms}$ and $53 \mathrm{~ms}$ acquisition times $)$ and 196 NOESY with a mixing time of 300 ms (likewise with $1024 \times 256$ complex data points and 213

$197 \mathrm{~ms}$ and $53 \mathrm{~ms}$ acquisition times). The homonuclear spectra employed pre-saturation for the 198 suppression of any residual water signal. Heteronuclear ${ }^{1} \mathrm{H}-{ }^{13} \mathrm{C}-\mathrm{HSQC}$ spectra were acquired 199 sampling $2048\left({ }^{1} \mathrm{H}\right) \times 256\left({ }^{13} \mathrm{C}\right)$ complex data points around a ${ }^{13} \mathrm{C}$ carrier offset of in the $75 \mathrm{ppm}$ 200 and employing a spectral width of $80 \mathrm{ppm}$ in the ${ }^{13} \mathrm{C}$ dimension to sample ${ }^{13} \mathrm{C}$ signal for $16 \mathrm{~ms}$ 201 and ${ }^{1} \mathrm{H}$ signal for $160 \mathrm{~ms} .{ }^{1} \mathrm{H}-{ }^{13} \mathrm{C}-\mathrm{HSQC}$ TOCSY spectra were acquired sampling $202512\left({ }^{1} \mathrm{H}\right) \times 256\left({ }^{13} \mathrm{C}\right)$ complex data points around a ${ }^{13} \mathrm{C}$ carrier offset of in the $75 \mathrm{ppm}$ and 
203 employing a spectral width of $80 \mathrm{ppm}$ in the ${ }^{13} \mathrm{C}$ dimension to sample ${ }^{13} \mathrm{C}$ signal for $16 \mathrm{~ms}$ and $204{ }^{1} \mathrm{H}$ signal for $128 \mathrm{~ms}$. In addition, ${ }^{1} \mathrm{H}-{ }^{13} \mathrm{C}-\mathrm{HMBC}$ spectra were acquired sampling

$2052048\left({ }^{1} \mathrm{H}\right) \times 400\left({ }^{13} \mathrm{C}\right)$ complex data points around a ${ }^{13} \mathrm{C}$ carrier offset of in the $100 \mathrm{ppm}$ and 206 employing a spectral width of $200 \mathrm{ppm}$ in the ${ }^{13} \mathrm{C}$ dimension to sample ${ }^{13} \mathrm{C}$ signal for $10 \mathrm{~ms}$ and $207{ }^{1} \mathrm{H}$ signal for $200 \mathrm{~ms}$. The sample was subsequently saponified for $3 \mathrm{~h}$ in $0.1 \mathrm{M} \mathrm{NaOH}$ at $45^{\circ} \mathrm{C}$ in 208 the dark and the same suite of NMR spectra was acquired on the saponified sample. A 1,5- $\alpha$-L209 arabinan (Megazyme) was dissolved in $\mathrm{D}_{2} \mathrm{O}$ and a high-resolution HSQC spectrum for the 210 sample was acquired serving as a reference standard. Assignment of molecular species was aided 211 by the acquired assignment spectra as well as by literature data ${ }^{51,52}$ for chemical shift 212 assignments in arabinoxylans. All spectra were processed with ample zero filling in all 213 dimensions using Topspin 4.0.6 (Bruker, Fällanden, Switzerland). Quantitative estimates for the 214 prevalence of different groups was likewise obtained by integration.

215 FGAX extract-based hydrogel formation. Hydrogel formation by laccase catalyzed cross-

216 linking of FAs in the extracted FGAX was carried out in 2\% FGAX solutions in water at $\mathrm{pH} 6.5$.

217 The laccases were fungal laccases derived from the ascomycete Myceliophthora thermophila 218 (Mt) and the basidiomycete Pleurotus ostreatus (Po), respectively. The Mt laccase, MtL, was 219 donated by Novozymes A/S (Bagsværd, Denmark) and the Po laccase, PoL was purchased from 220 Sigma-Aldrich (St. Louis, MO). Both laccases were lyophilized preparations that were kept 221 frozen at $-20^{\circ} \mathrm{C}$ until use. For cross-linking, the FGAX reaction mixture was in each case mixed 222 with the laccase to give a laccase dose of $0.4 \mathrm{U} / \mathrm{ml}$ (syringaldazine units at $\mathrm{pH} 5.0$ ), equivalent to $2230.33 \mathrm{nkat} / \mathrm{mg}$ FGAX, in order to obtain gelation within a time frame of $60 \mathrm{~min}$. Laccase activity 224 was determined by monitoring the oxidation of syringaldazine (from Sigma-Aldrich (St. Louis, $225 \mathrm{MO})$ at $530 \mathrm{~nm}\left(\varepsilon=6.5 \cdot 10^{4} \mathrm{M}^{-1} \mathrm{~cm}^{-1}\right)$ during reaction at $25^{\circ} \mathrm{C}$. The standard assay reaction 226 mixture contained $25 \mu \mathrm{M}$ syringaldazine, $10 \%(\mathrm{v} / \mathrm{v})$ ethanol, $25 \mathrm{mM}$ sodium acetate $(\mathrm{pH} 5.0)$ and 
227 a suitable amount of enzyme to produce a linear absorbance increase within 5 minutes. Enzyme 228 activity was expressed in units (U), where one $1 \mathrm{U}$ was defined as the amount of enzyme required 229 to catalyze conversion of $1 \mu \mathrm{mol}$ of substrate per minute at the assay reaction conditions $(1 \mathrm{U}=$ 23016.67 nkat). In practice, the enzyme catalyzed oxidative cross-linking (i.e. FGAX gelation) was 231 initiated by adding laccase to the FGAX solution which was then immediately transferred to the 232 rheometer. The rheological analyses were based on small angle measurements on $40 \mathrm{~mm}$, $2330.9767^{\circ}$ cone plate with solvent trap in a Discovery HR-3 Rheometer (TA Instruments, New 234 Castle, DE, USA). Time sweeps were recorded for $4000 \mathrm{~s}$ at a strain of $0.6 \%$ and a frequency of $2351 \mathrm{~Hz}$. Measurements were performed in triplicates within the viscoelastic region at $25^{\circ} \mathrm{C}$. The 236 simultaneous diFA formation and FA consumption were determined by LC-MS as detailed 237 above. Samples for LC-MS analysis were taken during the laccase reaction at set time points 238 from $0-140$ min, inactivated, and saponified in $1 \mathrm{M} \mathrm{NaOH}$ as described above.

239 Molecular substrate docking. For preparation of the substrate docked DcXyn30 the only

240 crystal structure with a ligand bound (PDB: 2 Y 24$)^{27}$ was loaded into YASARA Structure

241 (Version 19.11.2, YASARA Biosciences GmbH, Vienna, Austria)..$^{53}$ One of the ligands bound in 242 the active site (imidazole) was deleted and the second ligand bound $\left(2^{2}-(4-O\right.$-methyl- $\alpha-\mathrm{D}-$ 243 glucuronyl)-xylotriose) was elongated with a fourth xylose residue at the reducing end using the 244 YASARA Build function. The resulting complex was energy-minimized using the built-in 245 minimization function (and the result was used to prepare Figure 4A). The acetylated ligand was 246 created by deleting one water molecule in the tunnel close to the active site and the respective 247 acetyl residue was built on C2 of the xylose in subsite -1 as described above. Subsequent energy 248 minimization resulted in the complex used to prepare Figure 4B. Ray-traced screenshots for the 249 figures were made using the in-build POV-Ray (Persistence of Vision Pty. Ltd., Williamstown, 250 Victoria, Australia; http://www.povray.org/) function of YASARA. 


\section{$252 \quad$ Results and Discussion}

253 Extraction of soluble FGAX. The enzymatic DcXyn30 catalyzed extraction process was

254 optimized with respect to $\mathrm{pH}$ and temperature in a statistically designed experiment.

255 The highest yield based on the SEC peak area ranging from 5-110 kDa was obtained at $\mathrm{pH}$

2565.2 and $39^{\circ} \mathrm{C}$ (Figure 1A and B). When using the amount of reducing ends as the indicator, a

257 similar $\mathrm{pH}$ optimum ( $\mathrm{pH} 5.4$ ), but a different temperature optimum of $48.6^{\circ} \mathrm{C}$ was found (Figure

$2581 \mathrm{C}$ and D). Based on the overlapping optimal areas using both quantification methods, the

259 common optimal temperature was $45^{\circ} \mathrm{C}$ and optimal $\mathrm{pH}$ was 5.3. On this basis we opted to

260 conduct extractions at $45^{\circ} \mathrm{C}, \mathrm{pH}$ 5.5. The combined $\mathrm{pH}$-temperature optimum for DcXyn30 has

261 not been reported previously, but an optimal $\mathrm{pH}$ of 5.5 has been used in previous studies of the

262 enzyme. ${ }^{26}$

263

264 
A

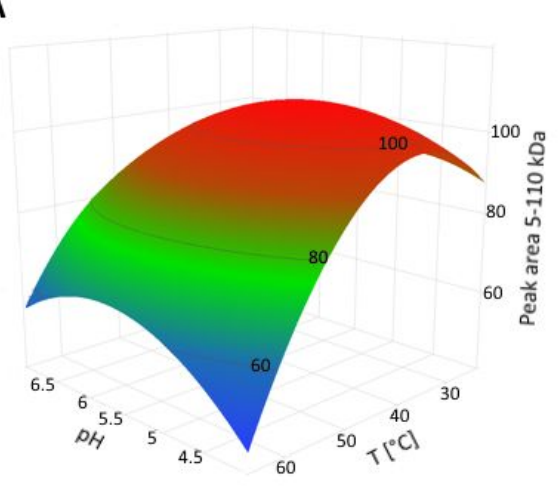

C

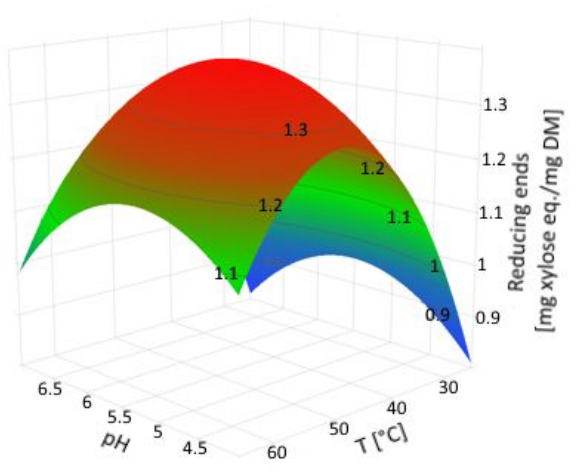

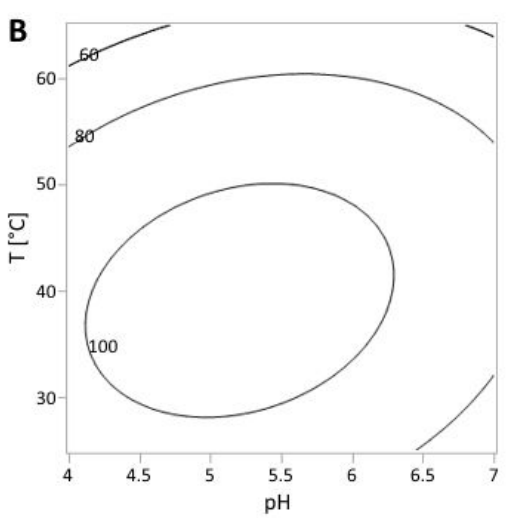

D

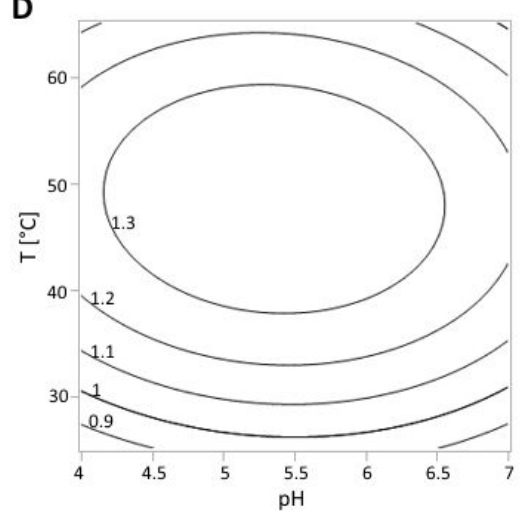

266 Figure 1: Enzymatic DcXyn30 extraction process optimization at different $\mathrm{pH}$ values $(4.0,5.5$, 267 7.0) and temperatures $\left(25,45,65^{\circ} \mathrm{C}\right)$. The reaction was carried out for $1 \mathrm{~h}$ in pH-adjusted $\mathrm{dH}_{2} \mathrm{O}$ 268 with $100 \mathrm{mg} / \mathrm{ml}$ destarched corn bran and $10 \mu \mathrm{g} / \mathrm{ml}$ purified DcXyn30. A) and B) Model based 269 on peak area (5 - $110 \mathrm{kDa})$ from SEC analysis. C) and D) Model based on reducing end analysis.

271 A detailed analysis of the SEC analysis data obtained during longer enzymatic treatment $(4 \mathrm{~h})$

272 with DcXyn30 showed that the broad main peak gradually "moved" to the right with time,

273 indicating that the average molecular weight of the extracted population of FGAX molecules

274 decreased only slowly from $\sim 41 \mathrm{kDa}$ to $\sim 10 \mathrm{kDa}$ during extended DcXyn30 reaction (Figure 2). 


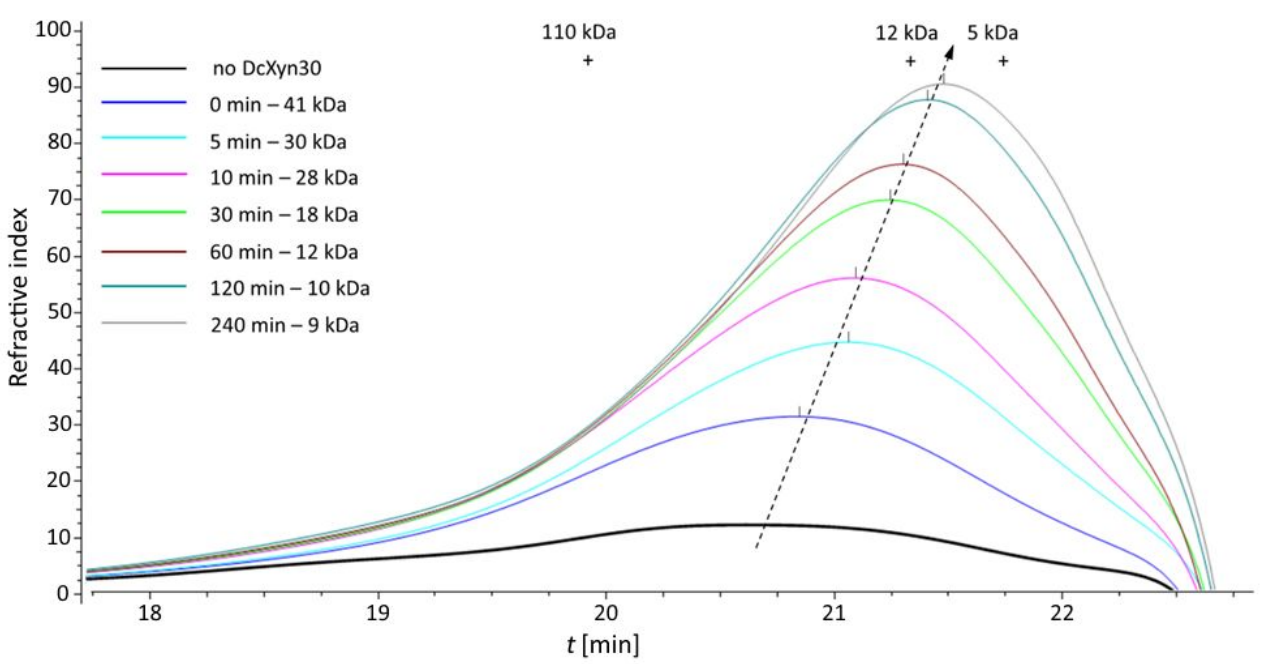

277 Figure 2: Time course of DcXyn30 catalyzed FGAX extraction from corn bran over 4 h: SEC

278 for FGAX extracts (standards of 5, 12 and $110 \mathrm{kDa}$ are indicated by +). The gradual decrease of 279 the molecular weight at the peak maximum is indicated by a dashed arrow. The insert to the left 280 lists the estimated average molecular weights of the extracted FGAX molecules at the different 281 time points. The sample at 0 min was taken immediately after addition of enzyme.

282 The highest overall yield was achieved after $2 \mathrm{~h}$ of incubation with DcXyn30 (Figure 2).

283 Further incubation did not lead to any significant increase in neither the peak area nor the 284 quantified reducing ends (Figure S1). This congruence between the level of reducing ends and 285 the total amount of the enzymatically extracted FGAX polysaccharides verify that the DcXyn30 286 had a very low preference for attacking the already released FGAX polysaccharides, supporting 287 that DcXyn30 catalyzed the selective release of stable, high molecular weight FGAX molecules

288 from corn bran. This result is explained by DcXyn30's well-defined recognition site for

289 cleavage, which requires presence of a GlcA residue on the second xylosyl downstream the

290 cleavage site. The data also support that the specific GlcA substitution pattern required for

291 GH30_8 xylanase cleavage occurs quite rarely in corn bran arabinoxylan. ${ }^{26,27}$ 
292 The relative amount of such a recognition site can be calculated as follows: Assuming a 293 theoretical xylan fragment of $110 \mathrm{kDa}$ in the original corn bran, which was cut to fragments of $29412 \mathrm{kDa}$ after one hour (Figure 2), would mean that the original fragment was cleaved eight times, 295 which corresponds to a relative amount of 1.4 mol- $\%$ of the recognition site for the GH30_8 296 xylanase.

297 Characterization of the extracted FGAX polymer. The yield of ethanol precipitated FGAX $298(3 \%$ (w of FGAX/w of initial corn bran), $6 \%$ (w of arabinoxylan/w of initial arabinoxylan in 299 corn bran)) obtained with the DcXyn30 treatment was higher, but comparable to previously 300 reported data for mild alkaline arabinoxylan extraction from corn bran (typical yields of $\sim 1.0 \%$ $301(\mathrm{w} / \mathrm{w})){ }^{54}$ The monosaccharide composition and FA content of the ethanol precipitated DcXyn30 302 released FGAX was compared to the full DcXyn30 released FGAX extract (w/o precipitation) 303 and to the destarched corn bran starting material. The monosaccharide and GlcA contents of the 304 destarched corn bran (Table 1) were in good agreement with previously reported values on the 305 same material, ${ }^{45}$ but the observed relatively higher level of DiFAs as compared to FA levels 306 contrasts previous findings (from our own lab). ${ }^{45}$ We ascribe the latter difference to the use of 307 more sensitive instrumentation in the present study, i.e. the LC-MS based quantitation versus the 308 conventional reverse phase HPLC analyses that we employed previously. ${ }^{45}$

309 Detailed comparison of the composition of the full DcXyn30 released FGAX extract, the 310 ethanol precipitated FGAX and the destarched corn bran starting material (Table 1) unveiled that 311 arabinose, xylose and GlcA contents were richest in the FGAX extracts, underlining that the 312 target FGAX polysaccharides were indeed extracted. The extracted FGAX polysaccharides were 313 particularly enriched in arabinose and GlcA by a factor $>2$ compared to the starting material, and 314 also rich in xylose and galacturonic acid (GalA) (1.1x and 1.4x compared to the corn bran) 
315 (Table 1). As expected, almost no glucose was extracted. The composition of the DcXyn30

316 released FGAX extract and the ethanol-precipitated FGAX extract did not differ significantly.

317 This verified that the raw extract indeed consisted mainly of the target FGAX polysaccharides.

318 The arabinose:xylose ratio of 1.18 of the ethanol-precipitated FGAX indicated an extremely

319 high degree of doubly arabinose-substituted xylosyls. To estimate the amount of single and

320 double arabinose-substitutions the following was considered: The composition analysis (Table 1)

321 showed that 15.5 mol- $\%$ of the xylosyls were acetylated and 5.6 mol- $\%$ carried a GlcA moiety.

322 The same amount (5.6 mol-\%) was assumed for un-substituted xylose, because DcXyn30

323 requires an un-substituted xylosyl unit next to the GlcA as recognition site. The molar percentage

324 of arabinose-decorated xylosyls in corn bran was then estimated as follows:

$325100 \%-15.5 \%$ (acetylation) $-5.6 \%$ (Gal subst. $)-5.6 \%$ (GlcA subst. $)-5.6 \%$ (unsubst. xylose $)=67.7 \%$

326 Hence, the amount of xylose carrying at least one arabinose-substitution is therefore estimated

327 to be $203 \mathrm{~g} / \mathrm{kg} \mathrm{DM}(0.677 \cdot 300 \mathrm{~g} / \mathrm{kg})$. Therefore, the percentage of arabinose moieties involved in

328 double arabinose-substitutions on xylose in the ethanol precipitated DcXyn30 can be calculated

329 to be: $((354-203) \cdot 100) / 300=50.3 \%$.

330 This estimate indicates that approx. $17 \%$ of the present xylosyl units carry a single arabinose

331 and that approx. $50 \%$ of the present xylosyl moieties are decorated with two arabinoses.

332 The data (Table 1) and the xylan substitution estimations imply the following: a) that the 333 DcXyn30 extracted FGAX is rich in esterified FAs that would be available for oxidative 334 enzymatic cross-linking, and b) that a fraction of the extracted FGAX appear to be cross-linked 335 already and is assumingly double-stranded FGAX (to be discussed further below). 
339 Table 1. Monosaccharide composition of the destarched corn bran, raw extract and the 340 ethanol precipitated DeXyn30 extracted FGAX.

\begin{tabular}{lrrr}
\hline Amount (g/kg DM) & Destarched corn bran & Full FGAX extract & $\begin{array}{r}\text { Ethanol-precipitated } \\
\text { FGAX extract }\end{array}$ \\
\hline Arabinosyl & $160 \pm 2.7$ & $350 \pm 4.7$ & $354 \pm 5.0$ \\
Galactosyl & $42.8 \pm 0.8$ & $16.8 \pm 0.0$ & $20.3 \pm 0.0$ \\
Glucosyl & $200 \pm 5.1$ & $10.3 \pm 1.6$ & $7.6 \pm 0.0$ \\
Xylosyl & $261 \pm 4.5$ & $311 \pm 6.3$ & $300 \pm 7.4$ \\
Mannosyl & $11.4 \pm 0.6$ & $2.24 \pm 0.0$ & $1.1 \pm 0.2$ \\
Galacturonic Acid & $10.4 \pm 2.0$ & $12.9 \pm 0.7$ & $14.9 \pm 0.5$ \\
Glucuronic Acid & $10.5 \pm 0.2$ & $21.1 \pm 1.3$ & $21.8 \pm 0.3$ \\
Sugar total & $696 \pm 16$ & $724 \pm 15$ & $720 \pm 13$ \\
\hline Ferulate & $18.2 \pm 0.8$ & $16.8 \pm 0.1$ & $21.8 \pm 0.2$ \\
Diferulate & $23.0 \pm 0.7$ & n.d. & $12.0 \pm 1.8$ \\
Acetyl & n.d. & n.d & $18.6 \pm 1.1$ \\
Lignin & $7.0 \pm 0.3$ & n.d & n.d \\
Loss (analytical loss) & 255.3 & n.d & 314.0 \\
\hline
\end{tabular}

n.d.: not determined; all values are averages of three independent experiments given \pm s.d.

343 Whereas the FA content in the FGAX extract was similar to the level in the starting material,

344 the content of diFAs in the precipitated FGAX extract was a factor of $\sim 2$ lower than that in the

345 starting corn bran material. The latter result is not surprising as it is a generally accepted

346 hypothesis that the presence of diFAs impedes enzymatic access to the xylan backbone as the

347 diFAs cross-link the arabinoxylan chains and may be involved in xylan coupling to lignin..$^{55,56}$

348 Based on the FA and DiFA content of the enzymatically extracted FGAX, we estimate that

$3497.3 \mathrm{~mol}-\%$ of all arabinoses in the FGAX carry a feruloyl (4.7 mol- $\%)$ or diferuloyl esterification

$350\left(2 \cdot 1.3\right.$ mol-\%) as modification, which is in accord with previous data. ${ }^{45}$ Additionally, the 
351 arabinose in the extracted FGAX may be modified with another xylose residue or a xylose-

352 galactose dimer via glycosidic linkages. However, from the available compositional data it is not

353 possible to calculate the amount of arabinose side-chain modifications by glycosidic linkages.

354 A deeper assessment of the levels of the DiFAs in the DcXyn30 released ethanol-precipitated

355 FGAX extract and the destarched corn bran showed that the relative levels of DiFAs were as

356 expected, i.e. with highest abundancy of 8-O-4 DiFA. ${ }^{57}$ However, the two most abundant DiFAs

357 (5-5' and 8-O-4') were depleted by a factor $>2$ in the FGAX extract compared to the level in the

358 starting material (Table 2), whereas the level of the other DiFAs in the FGAX extract was almost

359 similar to the level found in the original destarched corn bran (Table 2).

360

361 Table 2. Ferulic acid (FA) and diferulic acid (DiFA) content of the destarched corn bran, and the

362 ethanol precipitated FGAX extract.

\begin{tabular}{lrr}
\hline Amount (g/kg DM) & Destarched corn bran & $\begin{array}{r}\text { Ethanol-precipitated } \\
\text { FGAX extract* }\end{array}$ \\
\hline Ferulate & $18.2 \pm 0.8$ & $21.2 \pm 0.2$ \\
8-8' aryl DiFA & $4.04 \pm 0.31$ & $3.64 \pm 0.34$ \\
8-8' DiFA & $0.14 \pm 0.02$ & $0.38 \pm 0.07$ \\
8-5' DiFA & $1.04 \pm 0.03$ & $1.24 \pm 0.35$ \\
5-5' DiFA & $4.90 \pm 0.10$ & $1.38 \pm 0.43$ \\
8-O-4' DiFA & $10.6 \pm 0.1$ & $4.09 \pm 0.25$ \\
8-5' benzo DiFA & $2.75 \pm 0.08$ & $1.23 \pm 0.36$
\end{tabular}

n.d.: not determined; values represent the average and standard deviation of three independent 364 experiments. *DiFA levels in the full extract were below the detection limit.

365 The depletion of the $8-\mathrm{O}-4$ ' DiFA might be due to its higher vulnerability to cleavage 366 compared to the other DiFAs. Based on this finding, we further speculate that the 8-8' aryl DiFA 367 might be an exclusive feature of the extracted FGAX, which is found in lower amounts in other 
368 parts of the corn bran xylan and/or cell wall components (only trace amounts of triferulic acids 369 were detected and not included in the quantifications).

370 The NMR spectrum of the precipitated FGAX affirmed the presence of glucurono-arabino371 xylan (Figure 3A). Detailed analysis of the arabinofuranosyl signals (Figure 3B and Figure S2) 372 confirmed the high degree of arabinose double-substitutions. Also, presence of (low amounts of) 373 arabinose-xylose side-chains was confirmed. To assess the calculations based on the composition 374 data, a semi-quantitative analysis of the 2D-NMR data was carried out. Analysis of the spectra 375 before and after sample saponification (Figure S3) revealed that 19 mol- $\%$ of the xylose was 376 acetylated, which is in agreement with the 15.5 mol-\% estimated above. The NMR data also 377 supported an arabinose feruloylation/diferuloylation degree of 7.3 mol- $\%$ with an estimated 378 feruloylation degree of 10 mol- $\%$. Furthermore, the NMR data suggested a molar ratio of 379 arabinose:xylose:uronic acids of 8.6:6.3:1 (spectral regions for GlcA and GalA overlapped in the 380 FGAX NMR spectra). The ratio of double:single arabinose substitutions on the backbone as 381 determined by NMR supported the ratio of 2.9:1. The high arabinose:xylose ratio led us to re382 investigate presence of other sources for arabinose than arabinoxylan. Comparison of the 2D383 NMR spectra of the precipitated FGAX with linear 1,5- $\alpha$-L-arabinan (Figure 3C) indeed showed 384 presence of 1,5- $\alpha$-L-arabinan. It cannot be definitively concluded that the dimeric (or any 385 oligomeric) 1,5- $\alpha$-L-arabinan is not originating from low levels of pectin in the FGAX extract.

386 However, oligomeric arabinofuranosyl sidechains have previously been reported on xylan 387 isolated from corn kernels ${ }^{6,7}$ as well as from sorghum ${ }^{58}$ and bark of cinnamon trees based on 388 linkage analysis data. ${ }^{59}$ The NMR data here (Figure 3) are the first spectroscopic evidence of 389 arabinan-like side-chains in FGAX from corn bran. Only for sorghum glucuronoarabinoxylan 390 presence of oligomeric arabinosyl sidechains has previously been shown by NMR. ${ }^{58}$ 

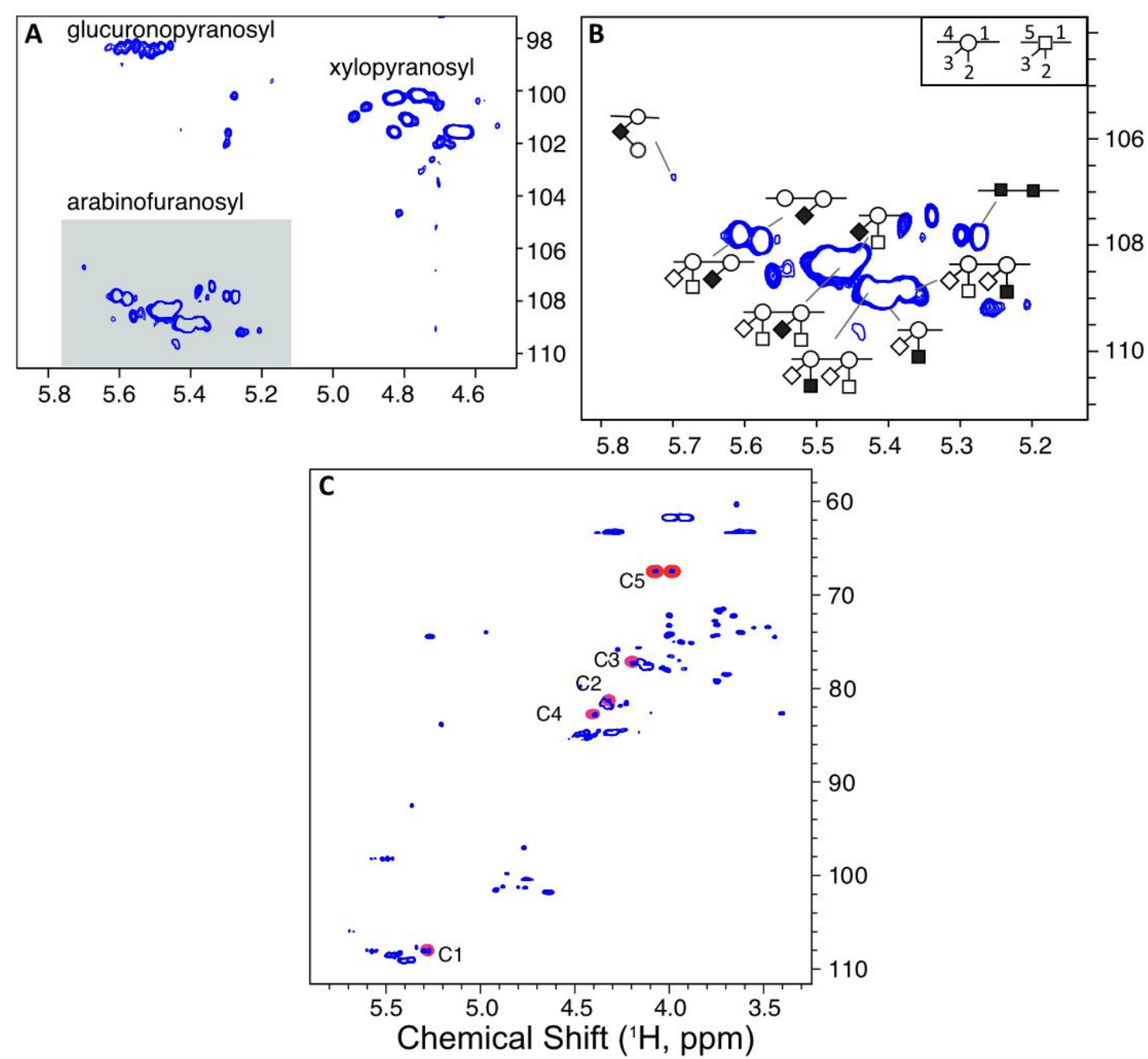

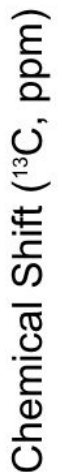

392 Figure 3: ${ }^{1} \mathrm{H}-{ }^{13} \mathrm{C}$ HSQC NMR spectra of the FGAX extract. A) 2D spectrum highlighting the

393 glucuronopyranosyl, xylopyranosyl and arabinofuranosyl signals. B) Zoom into the

394 arabinofuranosyl area highlighted as a grey box in A). Xylose units are shown as circles and

395 arabinoses as squares. The glycosidic bonds are shown as schematically depicted in the upper

396 right corner of B). The residue responsible for a specific anomeric signal is highlighted in black.

397 C) Overlayed 2D spectra of precipitated extracted FGAX (blue signals) and of pure 1,5-arabinan

398 (red signals). The carbon atoms of arabinose residues in the pure arabinan were assigned to

399 specific signals by the use of heteronuclear assignment spectra (Figure S2) and validated by

400 comparison to literature assignments. ${ }^{60}$ 
401 Substitution pattern of the GH30_8 recognition site in FGAX. We wanted to obtain more 402 insight into the substitution pattern close to the recognition site of the GH30_8 enzymes 403 including a GlcA residue. The available crystal structure of DcXyn3027 was therefore 404 investigated and two substrate analogues were docked into the active site (Figure 4A and B).

405 This docking revealed that the xylosyl in subsite +1 can carry substitutions on either $\mathrm{O} 2 \mathrm{and} / \mathrm{or}$ 406 O3. Even an arabinosyl residue in both positions would be possible based on the available cavity 407 volume in the enzyme. Decorations on the xylosyl in subsite -3 appear slightly more restricted. 408 The enzyme can apparently not accommodate an arabinosyl in position O2, but an acetyl residue 409 in that position as well as any substituent (arabinosyl or acetyl) on O3 would be possible. Such 410 an arabinosyl residue in proximity to a GlcA was described for xylan from corn stover, so a 411 substitution in this position seems plausible ${ }^{61}$ This finding could also explain the recalcitrance of 412 corn GAX towards degradation by xylanases from family GH10, which were shown to cleave 413 the xylan backbone in between an unsubstituted xylosyl and a GlcA-decorated xylosyl residue. ${ }^{62}$ 414 The presence of an acetyl residue on $\mathrm{O} 3$ of the same xylosyl carrying the GlcA was described 415 also, ${ }^{61}$ which seems plausible with respect to space requirements in the active site of DcXyn30. 416 An arabinosyl residue in that position is, however, too big to be accommodated by the enzyme.

417 The most restricted xylosyl residue in terms of substitutions is the xylosyl in subsite -1 . The $418 \mathrm{O} 3$ of this residue has to be unsubstituted, because binding in the very narrow cleft (Figure 4A) 419 close to the catalytic amino acid (E165) would otherwise not be possible. However, we found a 420 small tunnel in the structure just next to E165, which hosted three water molecules in the 421 structure. ${ }^{27}$ Docking of an acetyl modified substrate analogue revealed that such an acetyl would 422 fit perfectly into this tunnel upon binding (Figure 4B). 


\section{A}

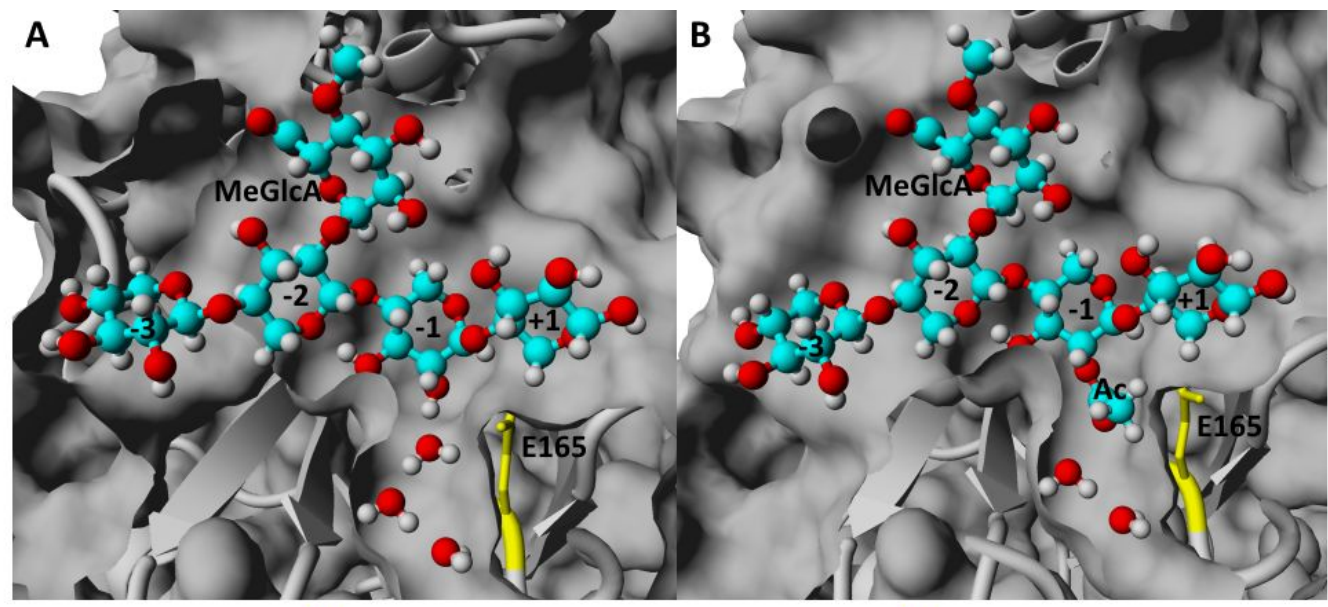

C

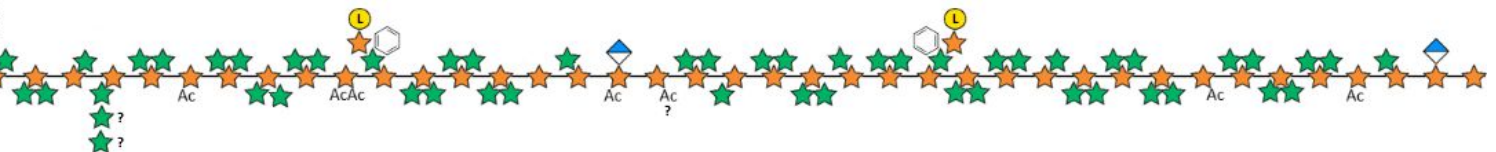

D

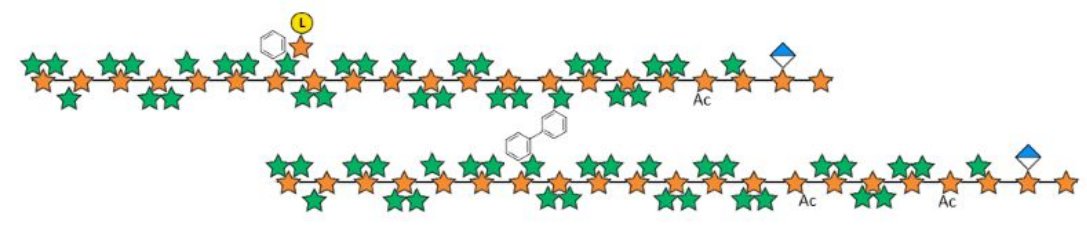

425 Figure 4: A and B: Active site 3D model representation of DcXyn30 with a substrate molecule

426 docked. The enzyme and its surface are shown in grey, the catalytic residue (E165) is highlighted

427 in yellow. The docked substrate and specific water molecules in the structure are shown as ball-

428 and-stick models with hydrogen atoms in white, carbon atoms in cyan and oxygen atoms in red.

429 The substrate binding sites and the cleavage site are indicated by the numbers -3 to +1 (the

430 substrate is cleaved between -1 and +1$)$. A: The substrate used for docking was $2^{3}-(4-O$-methyl-

$431 \alpha$-D-glucuronyl)-xylotetraose, B: The substrate used for docking was $2^{2}$-(acetyl)-23-(4-O-methyl-

$432 \alpha$-D-glucuronyl)-xylotetraose. C and D: Stylized structures of $16 \mathrm{kDa}$ FGAX fragments based on

433 our interpretation of the data. Orange stars: xylosyl, green stars: arabinosyl, blue/white diamond:

434 GluA, yellow circle: galactose (L indicates L-galactose), phenol ring: feruloyl residue, two

435 connected phenol rings: diferuloyl cross-link, Ac: acetyl residue. Positions of the substituents

436 (above or below) on the xylan backbone do not reflect actual bonds to specific carbon atoms. 
437 Due to the significant amounts of DiFAs in the enzymatically extracted FGAX we speculate 438 that it must contain a certain number of fragments that are already cross-linked, and we thus 439 presume that the DcXyn30 catalysis release both single-stranded and double-stranded FGAX 440 molecules, where the double-stranded molecules are DiFA-cross-linked (Figure 4D).

441 FGAX-based hydrogel formation. Oxidative gelation of 2\% FGAX solutions by enzymatic cross442 linking was catalyzed by laccases from Myceliophthora thermophila (MtL) and Pleurotus

443 ostreatus (PoL) which were dosed according their activity on syringaldazine (equivalent activity 444 at $\mathrm{pH}$ 5.0). The development of storage (G') and loss (G') moduli during the cross-linking was 445 studied over time (Figure 5A). Both laccases catalyzed oxidative cross-linking that resulted in 446 gel formation as evident from the increase of G' according to a regular hyperbola curve. The G' 447 of FGAX solutions, in which oxidative cross-linking was catalyzed by MtL increased with time 448 almost instantaneously after start of the reaction (after $2 \mathrm{~min}$.). The initial rate of gelation was 449 determined from the initial slope of G' as a function of time for $\mathrm{G}^{\prime}>\mathrm{G}^{\prime}$ ', yielding an average 450 gelation rate of $0.47 \pm 0.06 \mathrm{~Pa} \mathrm{~min}^{-1}$. In contrast, FGAX solutions in which oxidative cross-linking 451 was catalyzed by PoL showed a lag-phase of $\sim 25 \min$ (Figure 5A) before the G' started to 452 increase with an average gelation rate of $0.27 \pm 0.06 \mathrm{~Pa} \mathrm{~min}^{-1}$. The lag-phase and lower gelation 453 rate achieved with PoL catalysis suggest that MtL catalyzed oxidation of the feruloyls faster than 454 PoL. Apparently, a threshold concentration of DiFA had to be obtained before gel formation was 455 reflected in the rheological measurements; hence, from the analogous chemical analyses of the 456 laccase catalyzed formation of DiFA and depletion of FA (Figure 5B), it was evident that the 457 formation of DiFA also occured at a higher rate with MtL than with PoL catalysis. MtL catalysis 458 thus resulted in a DiFA concentration of $1.8 \mathrm{mM}$ after $5 \mathrm{~min}$, whereas it took more than $20 \mathrm{~min}$ 459 to reach a DiFA level above $1.5 \mathrm{mM}$ with the PoL (Figure 5B). 


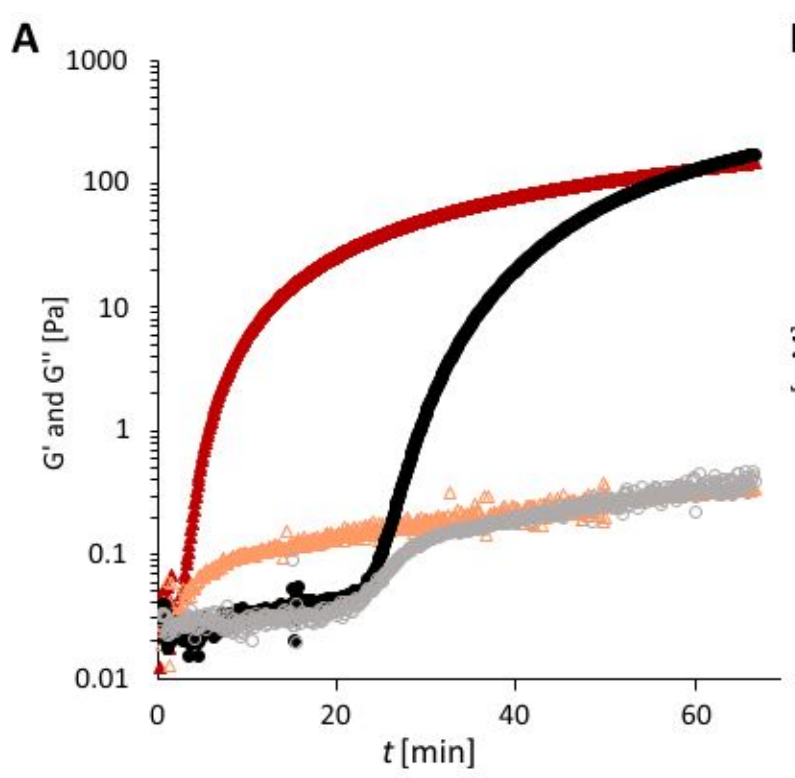

C

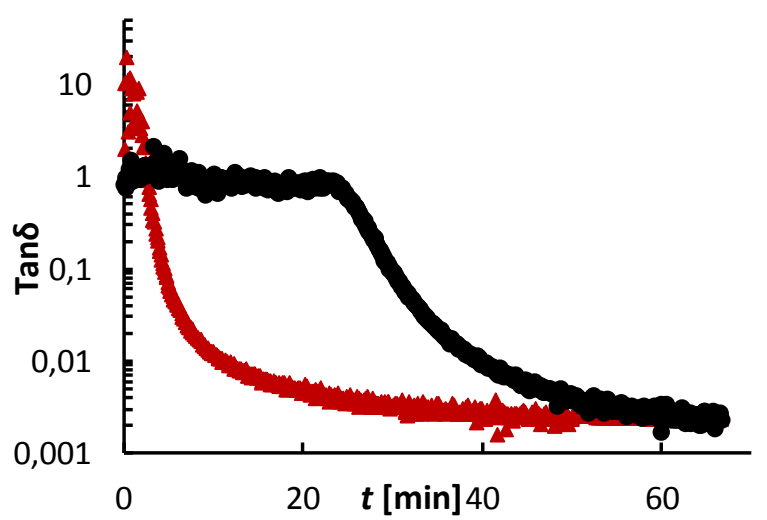

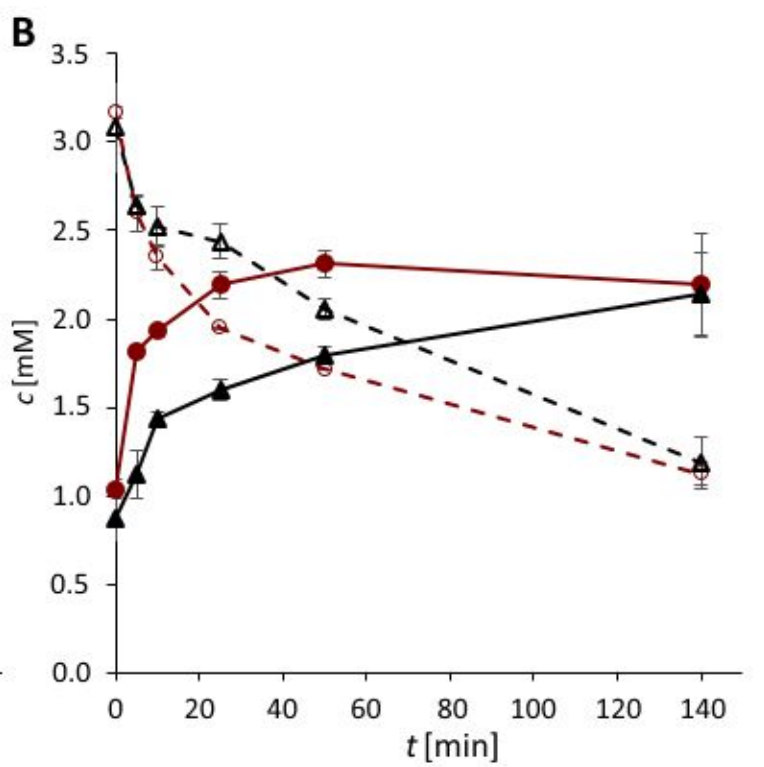

462 Figure 5: A) Progress in hydrogel formation of DcXyn30 extracted FGAX over time during

463 enzymatic catalysis with MtL (red and orange triangles) and PoL (black and grey circles),

464 respectively, measured as increase in elastic modulus (G', red and black closed symbols) and

465 viscous modulus (G', orange and grey open symbols). B) Formation of diferulic acids (DiFAs,

466 closed symbols) and loss in ferulic acid (FA, open symbols) concentration in DcXyn30 extracted

467 FGAX over time during MtL (red circles) and PoL (black triangles) catalytic treatment.

468 C) Progress in the loss factor $\tan \delta\left(\mathrm{G}^{\prime}, \mathrm{G}^{\prime}\right)$ with time during laccase catalyzed hydrogel

469 formation of DcXyn30 extracted FGAX with MtL (red) and PoL (black), respectively. 
470 The evolution of the elastic behavior plotted at the progress in the loss factor $\tan \delta$ with time 471 (Figure 5C) further verified that the phase transition from solution to gel happened rapidly and 472 continuously with MtL catalysis, whereas gel formation only started after ca. 25 min with the 473 PoL treatment. However, after $60 \mathrm{~min}$ (at the end of the treatment) the $\tan \delta$ values for the gels 474 formed by the two different laccase treatments were similar (Figure 5C). Together with the 475 gelation kinetics assessed from the progress in elastic modulus (G') and viscous modulus (G') 476 (Figure 5A) and the chemical data (Figure 5B), the data corroborate that the reaction first 477 involves a rapid formation of covalent bonds between the FA moieties of neighboring chains of 478 FGAX; and then progresses to produce a cross-linked polymer network; further the network 479 obtained with either laccase appeared to display similar gel properties after extended reaction.

480 The cross-linking experiments were accomplished with the FGAX solution at $\mathrm{pH}$ 6.5. Control 481 assays at $\mathrm{pH} 6.5$ (with syringaldazine) verified that the activities of the MtL were similar at $\mathrm{pH}$ 4825.0 and 6.5 ; whereas the PoL activity at $\mathrm{pH} 6.5$ (in the syringaldazine assay) was only $\sim 25 \%$ of 483 the activity at $\mathrm{pH}$ 5.0. The data are in accord with the reported $\mathrm{pH}$ optima for PoL, which are 484 typically in the range of $\mathrm{pH} 3-5,{ }^{63,64}$ whereas for $\mathrm{MtL}$ a slightly higher $\mathrm{pH}$ optimum range of $485 \mathrm{pH}$ 5.8-6.5 has been reported. ${ }^{65-67}$ We therefore ascribe the differences in the laccase catalyzed 486 cross-linking rates, and hence the lag-phase of the PoL reaction, to differences in $\mathrm{pH}$ optima for 487 the two laccases. 


\section{Conclusions}

490 The enzymatically extracted FGAX molecules turned out to contain diferulates in addition to

491 single feruloyl-substitutions leading us to interpret that the DcXyn30 catalysis on corn bran

492 released both single and double-stranded FGAX polysaccharides. Due to the distinct catalytic

493 selectivity of the DcXyn30, requiring a glucuronosyl (GlcA) or 4-O-methyl-GlcA residue as

494 recognition site for cleavage ${ }^{24}$, the solubilized FGAX molecules were essentially stable in

495 solution even during prolonged enzymatic treatment with DcXyn30. In addition to confirming a

496 high extent of doubly substituted xylosyl moieties having arabinosyl substitutions on both O2

497 and O3, NMR analysis also revealed the presence of dimeric (or oligomeric) 1,5- $\alpha$-L-arabinan in

498 the extracted corn bran FGAX. Although the possibility that these 1,5- $\alpha$-L-arabinan dimers

499 originate from pectin cannot be firmly excluded (low levels of pectin may be present in raw corn

500 bran), we consider it likely that these arabinan dimers are substitutions on the FGAX xylan.

501 Oligomeric arabinan sidechains have been reported on xylan from corn kernels ${ }^{6,7}$, sorghum ${ }^{58}$,

502 and from cinnamon tree bark $^{59}$, but the possible existence of such substitutions in corn bran

503 glucurono-arabinoxylan is a novel finding. Laccase catalyzed covalent cross-linking of the

504 feruloyl-groups to form DiFAs in the solubilized FGAX polysaccharides resulted in formation of

505 firm hydrogels. Rheological monitoring of the gel formation progress of the cross-linking

506 reactions showed that $M$. thermophila laccase catalyzed cross-linking was faster than the $P$.

507 ostreatus laccase, but the gels obtained had similar hardness and elasticity properties. We ascribe

508 the difference in cross-linking rate to activity differences of the two laccases at the cross-linking

$509 \mathrm{pH}$ of 6.5. The data present a new enzymatic approach using a highly selective GH30 xylanase to

510 catalyze release of long-chain FGAX from corn bran, and display functional utilization of FGAX

511 from corn bran, which could pave the way for novel bioeconomy valorization uses of corn bran. 


\section{Supporting Information}

513 The Supporting Information includes 3 Figures: Progress of DcXyn30 catalyzed FGAX extrac-

514 tion; HSQC and HMBC spectra for 1,5-arabinan; overlayed 2D spectra of precipitated FGAX

515 and saponified FGAX.

\section{Conflict of interest}

517 The authors declare no competing financial interests.

\section{Author Contributions}

519 ASM, PU, JM and LM perceived the study. JM did cloning, expression, and molecular docking 520 of DcXyn30. ML and LM analyzed corn bran, LM and KL optimized DcXyn30 extraction, SM

521 performed the NMR work and NMR data analysis, LM and AP did cross-linking and rheology,

522 and LM did all LC-MS analyses. The manuscript was written by LM, JM, and ASM with

523 contributions from all co-authors. All authors have approved the final version of the manuscript.

\section{Funding Sources}

525 This research was supported by the Innovation Fund Denmark (Project No. 5152-00001B). The

$526800 \mathrm{MHz}$ NMR spectra were acquired on instruments of the NMR center DTU funded by the

527 Villum Foundation.

\section{Acknowledgment}

529 We thank Novozymes (Bagsværd, Denmark) for donating the M. thermophila laccase and

530 Professor Maher Abou Hachem, DTU Bioengineering, for the 1,5- $\alpha$-L-arabinan sample.

\section{ABBREVIATIONS}

532 FGAX, glucuronoarabinoxylan; GH, glycoside hydrolase; DcXyn30, GH30_8 xylanase from

533 Dickeya chrysanthemi; GlcA, glucuronic acid; DM, dry matter; FA, ferulic acid; DiFA, diferulic 
534 acid; GalA, galacturonic acid; Gal, galactose; Ara, arabinose; Glc, glucose; Xyl, xylose; Man,

535 mannose; MtL, laccase from Myceliophtora thermophila; PoL, laccase from Pleurotus ostreatus.

536 REFERENCES

537 (1) Mahapatra, A.; Lan, Y. Postharvest Handling of Grains and Pulses. In Handbook of Food 538 Preservation; Rahman, M. S., Ed.; CRC Press, 1999; pp 74-129.

539 (2) United States Department of Agriculture: Foreign Agricultural Service. Grain: World $540 \quad$ Markets and Trade; 2019.

541 (3) Rose, D. J.; Inglett, G. E.; Liu, S. X. Utilisation of Corn (Zea mays) Bran and Corn Fiber 542 in the Production of Food Components. J. Sci. Food Agric. 2010, 90 (6), 915-924. $543 \quad$ https://doi.org/10.1002/jsfa.3915.

544 (4) Saulnier, L.; Marot, C.; Chanliaud, E.; Thibault, J. F. Cell Wall Polysaccharide 545 Interactions in Maize Bran. Carbohydr. Polym. 1995, 26 (4), 279-287. $546 \quad$ https://doi.org/10.1016/0144-8617(95)00020-8.

547 (5) Appeldoorn, M. M.; de Waard, P.; Kabel, M. A.; Gruppen, H.; Schols, H. A. Enzyme 548 Resistant Feruloylated Xylooligomer Analogues from Thermochemically Treated Corn 549 Fiber Contain Large Side Chains, Ethyl Glycosides and Novel Sites of Acetylation. 550 Carbohydr. Res. 2013, 381, 33-42. https://doi.org/10.1021/jf102849x.

551 (6) Huisman, M. M.; Schols, H.; Voragen, A. G. Glucuronoarabinoxylans from Maize Kernel 552 Cell Walls Are More Complex than Those from Sorghum Kernel Cell Walls. Carbohydr. 553 Polym. 2000, 43 (3), 269-279. https://doi.org/10.1016/S0144-8617(00)00154-5.

554 (7) Nishitani, K.; Nevins, D. J. Enzymic Analysis of Feruloylated Arabinoxylans (Feraxan) 
555 Derived from Zea mays Cell Walls. Plant Physiol. 1989, 91, 242-248. https://doi.org/ $556 \quad 10.1104 /$ pp.93.2.396.

557 (8) Appeldoorn, M. M.; Kabel, M. A.; Van Eylen, D.; Gruppen, H.; Schols, H. A. 558 Characterization of Oligomeric Xylan Structures from Corn Fiber Resistant to 559 Pretreatment and Simultaneous Saccharification and Fermentation. J. Agric. Food Chem. $560 \quad 2010,58(21), 11294-11301$. https://doi.org/10.1021/jf102849x.

561 (9) Allerdings, E.; Ralph, J.; Steinhart, H.; Bunzel, M. Isolation and Structural Identification 562 of Complex Feruloylated Heteroxylan Side-Chains from Maize Bran. Phytochemistry $563 \quad$ 2006, 67 (12), 1276-1286. https://doi.org/10.1016/j.phytochem.2006.04.018.

564 (10) Selig, M. J.; Adney, W. S.; Himmel, M. E.; Decker, S. R. The Impact of Cell Wall 565 Acetylation on Corn Stover Hydrolysis by Cellulolytic and Xylanolytic Enzymes. $566 \quad$ Cellulose 2009, 16 (4), 711-722. https://doi.org/10.1007/s10570-009-9322-0.

567 (11) Biely, P. Microbial Carbohydrate Esterases Deacetylating Plant Polysaccharides. 568

Biotechnol. $A d v$. 2012, $\quad 30$

$(6)$ $1575-1588$.

$569 \quad$ https://doi.org/10.1016/j.biotechadv.2012.04.010.

570 (12) Schendel, R. R.; Meyer, M. R.; Bunzel, M. Quantitative Profiling of Feruloylated 571 Arabinoxylan Side-Chains from Graminaceous Cell Walls. Front. Plant Sci. 2016, 6, $572 \quad$ 1249. https://doi.org/10.3389/fpls.2015.01249.

573 (13) Nordberg Karlsson, E.; Schmitz, E.; Linares-Pastén, J. A.; Adlercreutz, P. Endo574 Xylanases as Tools for Production of Substituted Xylooligosaccharides with Prebiotic 575 Properties. Appl. Microbiol. Biotechnol. 2018, 9081-9088. 
$576 \quad$ https://doi.org/10.1007/s00253-018-9343-4.

577 (14) Falck, P.; Linares-Pastén, J. A.; Karlsson, E. N.; Adlercreutz, P. Arabinoxylanase from 578 Glycoside Hydrolase Family 5 Is a Selective Enzyme for Production of Specific 579 Arabinoxylooligosaccharides. Food Chem. 2018, 242, 579-584. $580 \quad$ https://doi.org/10.1016/j.foodchem.2017.09.048.

581 (15) Niño-Medina，G.; Carvajal-Millan， E.; Rascon-Chu，A.; Marquez-Escalante，J. A.; 582 Guerrero, V.; Salas-Muñoz, E. Feruloylated Arabinoxylans and Arabinoxylan Gels: 583 Structure, Sources and Applications. Phytochem. Rev. 2010, 9 (1), 111-120. $584 \quad$ https://doi.org/10.1007/s11101-009-9147-3.

585 (16) Zhang, X.; Chen, T.; Lim, J.; Gu, F.; Fang, F.; Cheng, L.; Campanella, O. H.; Hamaker, 586 B. R. Acid Gelation of Soluble Laccase-Crosslinked Corn Bran Arabinoxylan and 587 Possible Gel Formation Mechanism. Food Hydrocoll. 2019, 92, 1-9. $588 \quad$ https://doi.org/10.1016/j.foodhyd.2019.01.032.

589 (17) Carvajal-Millan, E.; Landillon, V.; Morel, M.-H.; Rouau, X.; Doublier, J.-L.; Micard, V. 590 Arabinoxylan Gels: Impact of the Feruloylation Degree on Their Structure and Properties. 591 Biomacromolecules 2005, 6 (1), 309-317. https://doi.org/10.1021/bm049629a.

592 (18) Rose, D. J.; Inglett, G. E. Production of Feruloylated Arabinoxylo-Oligosaccharides from 593 Maize (Zea mays) Bran by Microwave-Assisted Autohydrolysis. Food Chem. 2010, 119 594 (4), 1613-1618. https://doi.org/10.1016/j.foodchem.2009.09.053

595 (19) Ruthes, A. C.; Martínez-Abad, A.; Tan, H.-T.; Bulone, V.; Vilaplana, F. Sequential 596 Fractionation of Feruloylated Hemicelluloses and Oligosaccharides from Wheat Bran 

597 Using Subcritical Water and Xylanolytic Enzymes. Green Chem. 2017, 19 (8), 1919- $598 \quad$ 1931. https://doi.org/10.1039/c6gc03473j

599 (20) Rudjito, R. C.; Ruthes, A. C.; Jiménez-Quero, A.; Vilaplana, F. Feruloylated 600 Arabinoxylans from Wheat Bran: Optimization of Extraction Process and Validation at 601 Pilot Scale. ACS Sustain. Chem. Eng. 2019, 7 (15), 13167-13177. 602 https://doi.org/10.1021/acssuschemeng.9b02329.

603 (21) Rasmussen, L. E.; Sørensen, J. F.; Meyer, A. S. Kinetics and Substrate Selectivity of a 604 Triticum aestivum Xylanase Inhibitor (TAXI) Resistant D11F/R122D Variant of Bacillus 605 subtilis XynA Xylanase. J. Biotechnol. 2010, $146 \quad$ (4), 207-214. $606 \quad$ https://doi.org/10.1016/j.jbiotec.2010.02.012.

607 (22) Gao, D.; Uppugundla, N.; Chundawat, S. P.; Yu, X.; Hermanson, S.; Gowda, K.; Brumm, 608 P.; Mead, D.; Balan, V.; Dale, B. E. Hemicellulases and Auxiliary Enzymes for Improved 609 Conversion of Lignocellulosic Biomass to Monosaccharides. Biotechnol. Biofuels 2011, 4, $610 \quad$ 5. https://doi.org/10.1186/1754-6834-4-5

611 (23) Rose, D. J.; Inglett, G. E. A Method for the Determination of Soluble Arabinoxylan 612 Released from Insoluble Substrates by Xylanases. Food Anal. Methods 2011, 4 (1), 66613 72. https://doi.org/10.1007/s12161-009-9121-0.

614 (24) Biely, P.; Singh, S.; Puchart, V. Towards Enzymatic Breakdown of Complex Plant Xylan 615 Structures: State of the Art. Biotechnol. Adv. 2016, 34 (7), 1260-1274. $616 \quad$ https://doi.org/10.1016/j.biotechadv.2016.09.001. 
617 (25) Nishitani, K.; Nevins, D. J. Glucuronoxylan Xylanohydrolase: A Unique Xylanase with 618 Requirement for Appendant Glucuronosyl Units. J. Biol. Chem. 1991, 266, 6539-6543.

619 (26) Vršanská, M.; Kolenová, K.; Puchart, V.; Biely, P. Mode of Action of Glycoside 620 Hydrolase Family 5 Glucuronoxylan Xylanohydrolase from Erwinia chrysanthemi. FEBS $621 \quad J .2007,274$ (7), 1666-1677. https://doi.org/10.1111/j.1742-4658.2007.05710.x.

622 (27) Urbániková, L.; Vršanská, M.; Mørkeberg Krogh, K. B. R.; Hoff, T.; Biely, P. Structural 623 Basis for Substrate Recognition by Erwinia chrysanthemi GH30 Glucuronoxylanase. $624 \quad F E B S J .2011,278$ (12), 2105-2116. https://doi.org/10.1111/j.1742-4658.2011.08127.x.

625 (28) Gallardo, Ó.; Fernández-Fernández, M.; Valls, C.; Valenzuela, S. V.; Blanca Roncero, M.; 626 Vidal, T.; Díaz, P.; Javier Pastor, F. I. Characterization of a Family GH5 Xylanase with 627 Activity on Neutral Oligosaccharides and Evaluation as a Pulp Bleaching Aid. Appl. 628 Environ. Microbiol. 2010, 76 (18), 6290-6294. https://doi.org/10.1128/AEM.00871-10.

629 (29) St. John, F. J.; Rice, J. D.; Preston, J. F. Characterization of XynC from Bacillus subtilis 630 subsp. subtilis Strain 168 and Analysis of Its Role in Depolymerization of 631 Glucuronoxylan. $\quad J . \quad$ Bacteriol. $\quad \mathbf{2 0 0 6}, \quad 188 \quad$ (24), $\quad 8617-8626$. 632 https://doi.org/10.1128/JB.01283-06.

633 (30) Sakka, M.; Tachino, S.; Katsuzaki, H.; van Dyk, J. S.; Pletschke, B. I.; Kimura, T.; Sakka, 634 K. Characterization of Xyn30A and Axh43A of Bacillus licheniformis SVD1 Identified by 635 Its Genomic Analysis. Enzyme Microb. Technol. 2012, 51 (4), 193-199. 636 https://doi.org/10.1016/j.enzmictec.2012.06.003.

637 (31) St. John, F. J.; Dietrich, D.; Crooks, C.; Balogun, P.; de Serrano, V.; Pozharski, E.; Smith, 
638 J. K.; Bales, E.; Hurlbert, J. A Plasmid Borne, Functionally Novel Glycoside Hydrolase 639 Family 30 Subfamily 8 Endoxylanase from Solventogenic Clostridium. Biochem. J. 2018, $640 \quad 475(9), 1533-1551$. https://doi.org/10.1042/BCJ20180050.x

641 (32) St. John, F. J.; Dietrich, D.; Crooks, C.; Pozharski, E.; González, J. M.; Bales, E.; Smith, $642 \quad$ K.; Hurlbert, J. C. A Novel Member of Glycoside Hydrolase Family 30 Subfamily 8 with 643 Altered Substrate Specificity. Acta Crystallogr. Sect. D Biol. Crystallogr. 2014, 70 (11), 644 2950-2958. https://doi.org/10.1107/S1399004714019531.

645 (33) Maehara, T.; Yagi, H.; Sato, T.; Ohnishi-Kameyama, M.; Fujimoto, Z.; Kamino, K.; 646 Kitamura, Y.; St. John, F. J.; Yaoi, K.; Kaneko, S. GH30 Glucuronoxylan-Specific 647 Xylanase from Streptomyces turgidiscabies C56. Appl. Environ. Microbiol. 2018, 84 (4), $648 \quad$ e01850-17. https://doi.org/10.1128/AEM.01850-17.

649 (34) Nakamichi, Y.; Fouquet, T.; Ito, S.; Watanabe, M.; Matsushika, A.; Inoue, H. Structural 650 and Functional Characterization of a Bifunctional GH30-7 Xylanase B from the 651 Filamentous Fungus Talaromyces cellulolyticus. J. Biol. Chem. 2019, 294 (11), 4065652 4078. https://doi.org/10.1074/jbc.ra118.007207.

653 (35) Katsimpouras, C.; Dedes, G.; Thomaidis, N. S.; Topakas, E. A Novel Fungal GH30 654 Xylanase with Xylobiohydrolase Auxiliary Activity. Biotechnol. Biofuels 2019, 12, 120. 655 https://doi.org/10.1186/s13068-019-1455-2.

656 (36) Biely, P.; Puchart, V.; Stringer, M. A.; Mørkeberg Krogh, K. B. R. Trichoderma reesei 657 XYN VI - A Novel Appendage-Dependent Eukaryotic Glucuronoxylan Hydrolase. FEBS $658 \quad J .2014,281$ (17), 3894-3903. https://doi.org/10.1111/febs.12925. 
659 (37) Šuchová, K.; Kozmon, S.; Puchart, V.; Malovíková, A.; Hoff, T.; Mørkeberg Krogh, K. B. 660 R.; Biely, P. Glucuronoxylan Recognition by GH 30 Xylanases: A Study with Enzyme 661 and Substrate Variants. Arch. Biochem. Biophys. 2018, 643, 42-49. 662 https://doi.org/10.1016/j.abb.2018.02.014.

663 (38) Puchart, V.; Mørkeberg Krogh, K. B. R.; Biely, P. Glucuronoxylan 3-O-Acetylated on 664 Uronic Acid-Substituted Xylopyranosyl Residues and Its Hydrolysis by GH10, GH11 and 665 GH30 Endoxylanases. Carbohydr. Polym. 2019, 205, 217-224. $666 \quad$ https://doi.org/10.1016/j.carbpol.2018.10.043.

667 (39) Biely, P.; Malovíková, A.; Hirsch, J.; Morkeberg Krogh, K. B. R.; Ebringerová, A. The 668 Role of the Glucuronoxylan Carboxyl Groups in the Action of Endoxylanases of Three 669 Glycoside Hydrolase Families: A Study with Two Substrate Mutants. Biochim. Biophys. 670 $\begin{array}{lllllll}\text { Acta } & - & \text { Gen. } & \text { Subj. } & \mathbf{2 0 1 5}, & 1850 \quad \text { (11), } & \text { 2246-2255. }\end{array}$ 671 https://doi.org/10.1016/j.bbagen.2015.07.003.

672 (40) Keen, N. T.; Boyd, C.; Henrissat, B. Cloning and Characterization of a Xylanase Gene 673 from Corn Strains of Erwinia chrysanthemi. Mol. Plant-Microbe Interact. 1996, 9 (7), 674 651-657. https://doi.org/10.1094/MPMI-9-0651.

675 (41) Bertani, I.; Passos da Silva, D.; Abbruscato, P.; Piffanelli, P.; Venturi, V. Draft Genome 676 Sequence of the Plant Pathogen Dickeya zeae DZ2Q, Isolated from Rice in Italy. Genome 677 Announc. 2013, l (6), e00905-e00913. https://doi.org/10.1128/genomeA.00905-13.

678 (42) Kumar, A.; Hunjan, M. S.; Kaur, H.; Rawal, R.; Kumar, A.; Singh. P. P. A Review on 679 Bacterial Stalk Rot Disease of Maize Caused by Dickeya zeae. J. Appl. Nat. Sci. 2017, 9 $680 \quad$ (2), 1214-1225. https://doi.org/10.31018/jans.v9i2.1348. 
681 (43) Zhou, J.; Cheng, Y.; Lv, M.; Liao, L.; Chen, Y.; Gu, Y.; Liu, S.; Jiang, Z.; Xiong, Y.; 682 Zhang, L. The Complete Genome Sequence of Dickeya zeae EC1 Reveals Substantial 683 Divergence from Other Dickeya Strains and Species. BMC Genomics 2015, 16, 571. 684 https://doi.org/10.1186/s12864-015-1545-x.

685 (44) Graham, D. C.; Dowson, W. J. The Coliform Bacteria Associated With Potato Black-Leg 686 And Other Soft Rots. Ann. Appl. Biol. 1960, 48 (1), 51-57. https://doi.org/10.1111/j.1744$687 \quad$ 7348.1960.tb03503.x.

688 (45) Agger, J. W.; Viksø-Nielsen, A.; Meyer, A. S. Enzymatic Xylose Release from Pretreated 689 Corn Bran Arabinoxylan: Differential Effects of Deacetylation and Deferuloylation on 690 Insoluble and Soluble Substrate Fractions. J. Agric. Food Chem. 2010, 58 (10), 6141$691 \quad$ 6148. https://doi.org/10.1021/jf100633f.

692 (46) Sluiter, A.; Hames, B.; Ruiz, R.; Scarlata, C.; Sluiter, J.; Templeton, D.; Crocker, D. 693 Determination of Structural Carbohydrates and Lignin in Biomass. Laboratory Analytical 694 Procedure (LAP); NREL/TP-510-42618, Golden, CO, 2008.

695 (47) Petersen, T. N.; Brunak, S.; von Heijne, G.; Nielsen, H. SignalP 4.0: Discriminating 696 Signal Peptides from Transmembrane Regions. Nat. Methods 2011, 8 (10), 785-786. 697 https://doi.org/10.1038/nmeth.1701.

698 (48) Waldron, K. W.; Parr, A. J.; Ng, A.; Ralph, J. Cell Wall Esterified Phenolic Dimers: 699 Identification and Quantification by Reverse Phase High Performance Liquid 700 Chromatography and Diode Array Detection. Phytochem. Anal. 1996, 7 (6), 305-312. $701 \quad$ https://doi.org/10.1002/(SICI)1099-1565(199611)7:6<305::AID-PCA320>3.0.CO;2-A. 
702 (49) Dobberstein, D.; Bunzel, M. Separation and Detection of Cell Wall-Bound Ferulic Acid 703 Dehydrodimers and Dehydrotrimers in Cereals and Other Plant Materials by Reversed 704 Phase High-Performance Liquid Chromatography with Ultraviolet Detection. J. Agric. $705 \quad$ Food Chem. 2010, 58 (16), 8927-8935. https://doi.org/10.1021/jf101514j.

706 (50) Andreasen, M. F.; Christensen, L. P.; Meyer, A. S.; Hansen, Å. Ferulic Acid 707 Dehydrodimers in Rye (Secale cereale L.). J. Cereal Sci. 2000, 31, 303-307. $708 \quad$ https://doi.org/10.1006/jcrs.1999.0296.

709 (51) Gruppen, H.; Hoffmann, R. A.; Kormelink, F. J. M.; Voragen, A. G. J.; Kamerlin, J. P.; 710 Vliegenthart, J. F. G. Characterisation by ${ }^{1} \mathrm{H}$ NMR Spectroscopy of Enzymically Derived 711 Oligosaccharides from Alkali-Extractable Wheat-Flour Arabinoxylan. Carbohydr. Res. $712 \quad 1992,233,45-64$. https://doi.org/10.1016/S0008-6215(00)90919-4.

713 (52) Petersen, B. O.; Lok, F.; Meier, S. Probing the Structural Details of Xylan Degradation by 714 Real-Time NMR Spectroscopy. Carbohydr. Polym. 2014, 112, 587-594. $715 \quad$ https://doi.org/10.1016/j.carbpol.2014.06.049.

716 (53) Krieger, E.; Vriend, G. YASARA View—Molecular Graphics for All Devices—from 717 Smartphones to Workstations. Bioinformatics 2014, 30 (20), 2981-2982. 718 https://doi.org/10.1093/bioinformatics/btu426.

719 (54) Morales-Burgos, A. M.; Carvajal-Millan, E.; López-Franco, Y. L.; Rascón-Chu, A.; 720 Lizardi-Mendoza，J.; Sotelo-Cruz，N.; Brown-Bojórquez，F.; Burgara-Estrella， A.; 721 Pedroza-Montero, M. Syneresis in Gels of Highly Ferulated Arabinoxylans: 
722 Characterization of Covalent Cross-Linking, Rheology, and Microstructure. Polymers $723 \quad 2017,9,164$. https://doi.org/10.3390/polym9050164

724 (55) Grabber, J. H.; Ralph, J.; Hatfield, R. D. Ferulate Cross-Links Limit the Enzymatic 725 Degradation of Synthetically Lignified Primary Walls of Maize. J. Agric. Food Chem. $726 \quad 1998,46(7), 2609-2614$. https://doi.org/10.1021/jf9800099

727 (56) Grabber, J. H.; Hatfield, R. D.; Ralph, J. Diferulate Cross-Links Impede the Enzymatic 728 Degradation of Non-Lignified Maize Walls. J. Sci. Food Agric. 1998, 77, 193-200. 729 https://doi.org/ 10.1002/(SICI)1097-0010(199806)77:2<193::AID$730 \quad$ JSFA25>3.0.CO;2-A.

731 (57) Mnich, E.; Bjarnholt, N.; Eudes, A.; Harholt, J.; Holland, C.; Jørgensen, B.; Larsen, F. H.; 732 Liu, M.; Manat, R.; Meyer, A. S.; et al. Phenolic Cross-Links: Building and de733 734 735 736 737 738 Constructing the Plant Cell Wall. Nat. Prod. Rep. 2020, https://doi.org/10.1039/c9np00028c.

(58) Verbruggen, M.; Spronk, B.; Schols, H. A.; Beldman, G.; Voragen, A. G. J.; Thomas, J.; Kamerling, J. P.; Vliegenthart, J. F. G. Structures of Enzymically Derived Oligosaccharides from Sorghum Glucuronoarabinoxylan. Carbohydr. Res. 1998, 306, 265-274. https://doi.org/10.1016/S0008-6215(97)10064-7

739 (59) Channe Gowda, D.; Sarathy, C. Structure of an L-Arabino-D-Xylan from the Bark of 740 Cinnamomum zeylanicum. Carbohydr. Res. 1987, 166 (2), 263-269. $741 \quad$ https://doi.org/10.1016/0008-6215(87)80062-9. 
742 (60) Cardoso, S.; Ferreira, J.; Mafra, I.; Silva, A.; Coimbra, M. Structural Ripening-Related 743 Changes of the Arabinan-Rich Pectic Polysaccharides from Olive Pulp Cell Walls. $J$. 744 Agric. Food Chem. 2007, 55 (17), 7124-7130. https://doi.org/10.1021/jf070769w.

745 (61) Naran, R.; Black, S.; Decker, S. R.; Azadi, P. Extraction and Characterization of Native 746 Heteroxylans from Delignified Corn Stover and Aspen. Cellulose 2009, 16 (4), 661-675. $747 \quad$ https://doi.org/10.1007/s10570-009-9324-y.

748 (62) Biely, P.; Vršanská, M.; Tenkanen, M.; Kluepfel, D. Endo- $\beta-1,4-X y l a n a s e$ Families: 749 Differences in Catalytic Properties. J. Biotechnol. 1997, 57, 151-166. https://doi.org/ $750 \quad 10.1016 / S 0168-1656(97) 00096-5$.

751 (63) Pozdnyakova, N. N.; Turkovskaya, O. V; Yudina, E. N.; Rodakiewicz-Nowak, Y. Yellow 752 Laccase from the Fungus Pleurotus ostreatus D1: Purification and Characterization. Appl. 753 Biochem. Microbiol. 2006, $\quad 42$ $(1)$, $56-61$.

$754 \quad$ https://doi.org/10.1134/S000368380601008X.

755 (64) Pozdnyakova, N. N.; Rodakiewicz-Nowak, J.; Turkovskaia, O. V. Catalytic Properties of 756 Yellow Laccase from Pleurotus ostreatus D1. J. Mol. Catal. B Enzym. 2004, 30, 19-24. $757 \quad$ https://doi.org/10.1016/j.molcatb.2004.03.005.

758 (65) Hollmann, F.; Gumulya, Y.; Tölle, C.; Liese, A.; Thum, O. Evaluation of the Laccase 759 from Myceliophthora thermophila as Industrial Biocatalyst for Polymerization Reactions. 760 Macromolecules 2008, 41 (22), 8520-8524. https://doi.org/10.1021/ma801763t. 
761 (66) Munk, L.; Andersen, M. L.; Meyer, A. S. Direct Rate Assessment of Laccase Catalysed 762 Radical Formation in Lignin by Electron Paramagnetic Resonance Spectroscopy. Enzyme 763 Microb. Technol. 2017, 106, 88-96. http://doi.org/10.1016/j.enzmictec.2017.07.006.

764 (67) Berka, R. M.; Schneider, P.; Golightly, E. J.; Brown, S. H.; Madden, M.; Brown, K. M.; 765 Halkier, T.; Mondorf, K.; Xu, F. Characterization of the Gene Encoding an Extracellular 766 Laccase of Myceliophthora thermophila and Analysis of the Recombinant Enzyme 767 Expressed in Aspergillus oryzae. Appl. Environ. Microbiol. 1997, 63 (8), 3151-3157. $768 \quad$ https://doi.org/10.1128/AEM.63.8.3151-3157.1997.

769 TOC graphic

\section{0}
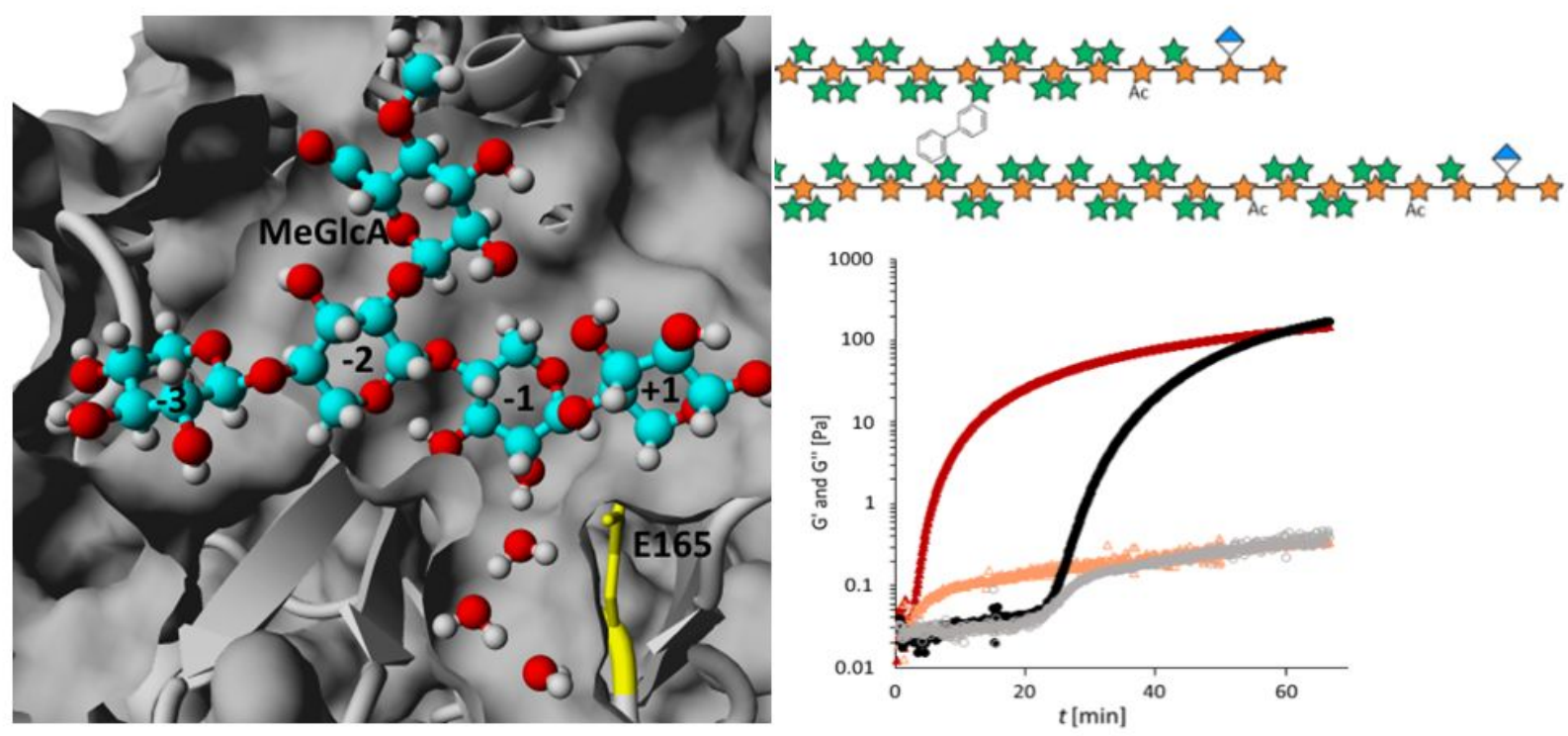

771

772 SYNOPSIS: A GH30 xylanase from Dickeya chrysanthemi was used to extract cross-linkable,

773 highly feruloylated, high-molecular weight glucuronoarabinoxylan from corn bran. 